\title{
New and additional records of Metharpinia Schellenberg, 1931 and Microphoxus Barnard, 1960 (Crustacea: Amphipoda: Phoxocephalidae) from Brazilian waters
}

\author{
Luiz F. Andrade' \& André R. Senna ${ }^{2}$ \\ 1 Universidade Federal Rural do Rio de Janeiro (UFRRJ), Decanato de Pesquisa e Pós-Graduação, \\ Programa de Pós-Graduação em Biologia Animal. Seropédica, RJ, Brasil. \\ ORCID: http://orcid.org/0000-0002-4868-737X. E-mail: Izflp.andrade@hotmail.com \\ 2 Universidade do Estado do Rio de Janeiro (UERJ), Centro de Educação e Humanidades (CEH), \\ Faculdade de Formação de Professores (FFP). São Gonçalo, RJ, Brasil. \\ ORCID: http://orcid.org/0000-0003-0976-849X. E-mail: senna.carcinologia@gmail.com
}

\begin{abstract}
New records of the species Metharpinia dentiurosoma Alonso de Pina, 2003, M. grandirama Alonso de Pina, 2003, M. iado Alonso de Pina, 2003, Microphoxus cornutus (Schellenberg, 1931) and Mi. uroserratus Bustamante, 2002 are reported for Brazilian waters. A discussion about the Metharpinia-Microphoxus complex is presented based on literature review and new observations of sampled species. Emended diagnoses are presented for the recorded species of Metharpinia and identification keys to world species of Metharpinia and Microphoxus are provided.
\end{abstract}

Key-Words. Southwestern Atlantic; Species complex; Argentina; Brazil; Chile.

\section{INTRODUCTION}

Among the collections of phoxocephalids amassed during the cruises of the R/V Prof. Wladimir Besnard conducted along the southeastern Brazilian coast (São Paulo, Rio de Janeiro and Santa Catarina) in 1970 and 1971 , between 15 and $98 \mathrm{~m}$, were three species of Metharpinia Schellenberg, 1931, and two of Microphoxus Barnard, 1960 representing new and additional records to the Brazilian coast.

These records are discussed herein. Opportunity was taken to redescribe and illustrate Metharpinia dentiurosoma, M. grandirama, M. iado Alonso de Pina, 2003, all previously known only from farther south (Argentina) and now recorded for the first time from Brazilian waters. Microphoxus cornutus (Schellenberg, 1931), originally described from Punta Arenas (Chile) and subsequently recorded from southeastern Brazil, and Mi. uroserratus Bustamante, 2002, originally described from southeastern Brazil, are recorded from additional Brazilian localities. Both species are redescribed and illustrated.

Identification keys to the world species of Metharpinia and Microphoxus are provided.

\section{MATERIAL AND METHODS}

The material studied herein was collected during the MBT (Mini Biological Trawl) Project from Instituto Oceanográfico, Universidade de São Paulo. All specimens were preserved in $70 \%$ ethanol and deposited at the Crustacea Collections of the Universidade do Estado do Rio de Janeiro (UERJ) and Museu de Zoologia da Universidade de São Paulo (MZUSP).

For the taxonomic study, the mouthparts and appendages were dissected and mounted in glycerin gel slides. The drawings were made under an optical microscope with camera lucida, Motic BA-310, and digitized with CorelDRAW 2018. The setal/spine classification adopted in this paper follows Garm \& Watling (2013) and the nomenclature of gnathopod palms is based on Poore \& Lowry (1997).

The identification key for the species of Microphoxus was in part updated from Bustamante (2002). As we have not had access to the types of the species currently included in Microphoxus, the key is based on personal observations and information from the literature. 


\section{RESULTS}

\section{Taxonomic account Order Amphipoda Latreille, 1816 Suborder Amphilochidea Boeck, 1871 Superfamily Haustorioidea Stebbing, 1906 Family Phoxocephalidae Sars, 1891 Genus Metharpinia Schellenberg, 1931}

Type species: Metharpinia longirostris Schellenberg, 1931.

Diagnosis (emended from Barnard \& Karaman, 1991; Alonso de Pina, 2003b): Rostrum constricted. Eyes present. Antenna 1, article 2 elongate or of medium length, ventral setae proximally placed. Antenna 2 , article 1 not ensiform, article 3 with 2 facial setules, facial stout setae on article 4 in 2 or more rows, article 5 ordinary in size. Right mandibular incisor with 3 teeth, right lacinia mobilis bifid, thin; molar not triturative, with 4 or more splayed stout setae; palpar hump small, apex of palp article 3 oblique. Inner plate of maxilla 1 with 4 setae, palp 2-articulate. Maxilliped ordinary, apex of palp article 3 weakly protuberant, article 4 elongate, apical nail distinct, partially fused. Gnathopods 1-2 ordinary, small, similar, carpus with ordinary length to elongate, free, without eusirid attachment, palms acute, propodus ordinary, ovatorectangular, poorly setose anteriorly. Pereopods 3-4, carpus with posteroproximal setae, propodus with stout facial setae. Pereopod 5-6, basis, merus and carpus broad. Pereopod 7, ischium and dactylus ordinary. Epimeral plates 1-2 with long posterior setae, epimeral plate 3 ordinary, bearing 4 or more long setae. Uropod 1-2, one or more rami with stout setae continuously to apex, with subapical stout setae or nails. Uropod 3, at least one of rami longer than peduncle, outer ramus 2-articulate, article 2 with 2-3 apical setae.

Composition of the genus: The genus is composed by 10 species: Metharpinia coronadoi Barnard, 1980; M. dentiurosoma Alonso de Pina, 2003; M. floridana (Shoemaker, 1933); M. grandirama Alonso de Pina, 2003; M. iado Alonso de Pina, 2003; M. jonesi (Barnard, 1963); M. longirostris Schellenberg, 1931; M. oripacifica Barnard, 1980; M. protuberantis Alonso de Pina, 2001; M. taylorae Andrade, Johnsson \& Senna, 2015.

\section{Metharpinia dentiurosoma Alonso de Pina, 2003} (Figs. 1-6)

Metharpinia dentiurosoma Alonso de Pina, 2003b: 2523, figs. 1-7. López-Gappa et al., 2006: 16, 52. Alonso \& Chiesa, 2014: 206, 207, 209, fig. 3C, E-I. Andrade et al., 2015: 39.

Material examined: 6 \%ᄋ, in 70\% ethanol, MBT 155, $22^{\circ} 22^{\prime} \mathrm{S}, 41^{\circ} 32^{\prime} \mathrm{W}, 34 \mathrm{~m}$ depth, Rio de Janeiro state, 05 September 1970 (UERJ 412); 7 \%o, in 70\% ethanol, MBT $155,22^{\circ} 22^{\prime} \mathrm{S}, 41^{\circ} 32^{\prime} \mathrm{W}, 34 \mathrm{~m}$ depth, Rio de Janeiro state,
05 September 1970 (MZUSP 41105); $1 \%$, in 70\% ethanol, MBT 217, 230' $\mathrm{S}, 42^{\circ} 41^{\prime} \mathrm{W}, 45 \mathrm{~m}$ depth, Rio de Janeiro state, 05 June 1971 (UERJ 410); 4 \%\%, in 70\% ethanol, MBT 217, 2300'S, $42^{\circ} 41^{\prime} \mathrm{W}, 45 \mathrm{~m}$ depth, Rio de Janeiro state, 05 June 1971 (UERJ 413); 4 o\%, in 70\% ethanol, MBT 217, 230' $\mathrm{S}, 42^{\circ} 41^{\prime} \mathrm{W}, 45 \mathrm{~m}$ depth, Rio de Janeiro state, 05 June 1971 (MZUSP 41104); $1 \%$ and $10^{\circ}$, in 70\% ethanol, MBT 140, $23^{\circ} 02^{\prime} \mathrm{S}, 43^{\circ} 00^{\prime} \mathrm{W}, 40 \mathrm{~m}$ depth, Rio de Janeiro state, 02 September 1970 (UERJ 416); 1 \%, in

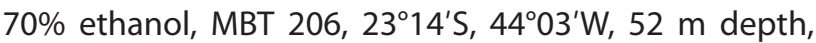
Rio de Janeiro state, 03 June 1971 (UERJ 417); 4 우, in $70 \%$ ethanol, MBT 50, $23^{\circ} 39^{\prime} \mathrm{S}, 45^{\circ} 06^{\prime} \mathrm{W}, 28 \mathrm{~m}$ depth, São Paulo state, 08 May 1970 (UERJ 415); 1 \%, dissected and drawn, MBT 81, 244' S, 4558'W, 72 m depth, São Paulo state, 16 June 1970 (UERJ 409); $10^{\circ}$, dissected and drawn,

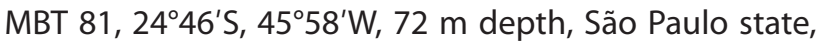
16 June 1970 (UERJ 411); 6 우, in 70\% ethanol, MBT 81, $24^{\circ} 46^{\prime} \mathrm{S}, 45^{\circ} 58^{\prime} \mathrm{W}, 72 \mathrm{~m}$ depth, São Paulo state, 16 June 1970 (UERJ 414); 1 \%, in 70\% ethanol, MBT 129, 29¹3'S, $49^{\circ} 25^{\prime} \mathrm{W}, 27 \mathrm{~m}$ depth, Santa Catarina state, 25 June 1970 (UERJ 418).

Diagnosis: Head, eyes rounded and medium-sized; rostrum constricted, narrow, elongate and spatulate. Antenna 1, peduncle article 2 elongate. Antenna 2, peduncle article 4 , with 4 rows of facial stout setae. Mandible molar as a small hump with stout setae, left lacinia mobilis flabellate, right lacinia mobilis bifid. Maxilla 1, inner plate with 4 plumose setae; palp 2-articulate. Maxilliped, inner plate with 2 stout setae apically; palp, article 4 narrow, with medium apical nail, partially embedded. Gnathopods 1-2, anterior margin weakly setose; palm acute, palmar hump large. Pereopod 7, basis, expanded posteroventrally, reaching apex of carpus. Epimeral plate 3, posterior margin weakly crenulate, posteroventral corner strongly produced into a large tooth. Urosomite 3, produced as a large acute hook dorsally. Uropods 1-2, peduncle, apicolateral corner serrate, rami with stout setae pointing upwards. Uropod 3, outer ramus longer than inner, article 2 elongate, with 2 apical setae. Telson, deeply cleft, apex truncate, with variable stout and simple setae on each side.

Description: Based on female (UERJ 409). Habitus as in Fig. 1. Head (Fig. 2A, B) eyes rounded and medium-sized; rostrum constricted, narrow, elongate and spatulate. Antenna 1 (Fig. $2 \mathrm{C}$ ), peduncle article 1 , about $1.5 \times$ longer than wide, ventral margin with brush setae, dorsal apex with 2 setae; article 2, ventral margin with a tuft of long setae; article 3, short, ventral margin with 3 setae; primary flagellum 12-articulate; accessory flagellum 8-articulate. Antenna 2 (Fig. 2D), peduncle article 4, facial stout setae formula: 1-3-5-4, ventral margin with brush setae and few simple with 1 stout seta distally; article 5, ventral margin with long and brush setae, facial margin with 5 stout setae medially and 3 stout setae distally; flagellum 14-articulate. Lower lip (Fig. 2J), outer lobes with setules apically. Left and right mandibles (Fig. 2l, H), left molar forming a small hump with 8 stout setae, right molar with 7 stout setae, left incisor with 2 
weak teeth, right incisor with 3 teeth, left lacinia mobilis flabellate, right lacinia mobilis bifid, accessory setal rows with 13 stout setae; palp 3-articulate, article 1 short, article 2 with 8 setae, article 3 slightly longer than article 2, with 3 setae, apex oblique, with 9 medium to long setae. Maxilla 1 (Fig. 2E), inner plate with 4 plumose setae; outer plate with 10 multicuspidate stout setae; palp 2-articulate, article 2 with 6 plumose and 3 stout setae. Maxilla 2 (Fig. 2F), inner plate with long setules and plumose setae; outer plate slightly longer than inner, setose apically. Maxilliped (Fig. 2G), inner plate with 7 plumose and 2 stout setae apically; outer plate with 2 slender and 7 stout setae; palp, article 1, with 1 apicolateral seta, article 2 with 2 setae laterally, medial margin moderately setose, article 3 moderately setose, article 4 narrow, with 1 medium apical nail, partially embedded.

Gnathopod 1 (Fig. 3A), coxa, subrectangular, ventral margin with 11 setae; basis, margins with short to long setae; ischium, small and subrectangular; merus, posterior margin weakly setose; carpus, anterior margin with 2 setae distally, posterior margin weakly setose; propodus, weakly setose, anterior margin with a tuft of setae distally, posterior margin with 1 stout seta defining palm; palm acute, with setules, palmar hump large; dactylus, slightly longer than palm. Gnathopod 2 (Fig. 3B), coxa, subrectangular, ventral margin with 17 setae; basis, margins with short to long setae; ischium, small and subrectangular, posterior margin with 1 seta; merus, posterior margin with a tuft of setae; carpus, anterior margin with 1 seta distally, posterior margin weakly setose; propodus, weakly setose, anterior margin with a tuft of setae distally, posterior margin with 1 stout seta defining palm; palm acute, with setules, palmar hump large; dactylus slightly longer than palm. Pereopod 3 (Fig. 3C), coxa, subrectangular, ventral margin with 11 setae; basis, anterior and posterior margins with short to medium setae; ischium, small and subrectangular, posterior margin with 2 setae; merus, anterior margin with 1 long seta, posterior margin weakly setose, facial margin with row of 4 setae distally; carpus, posterior margin weakly setose, with 1 subdistal thicker stout seta extending $65 \%$ of propodus; propodus, posterior margin with 7 stout setae; dactylus, about 55\% the length of propodus. Pereopod 4 (Fig. 3D), coxa, subtriangular, ventral margin with 18 short setae, posterodorsal margin weakly excavate; remaining articles are very similar to pereopod 3, differing only by some arrangements of setae. Pereopod 5 (Fig. 4A), coxa bilobate; basis subrectangular and thickening distally, anterior margin with short to long setae, posterior margin naked; ischium, small and subrectangular, anterior margin with row of 6 setae extending to facial margin; merus, margins weakly setose, facial margin with 5 rows of stout setae: 4-3-3-6-8; carpus, margins weakly setose, facial margin with 5 rows of stout setae: 2-2-2-3-7; propodus, margins weakly setose, anterior margin with 6 stout setae, posterior margin with 4 stout setae distally; dactylus, about $60 \%$ the length of propodus. Pereopod 6 (Fig. 4B), coxa, posterior margin with row of short setae; basis, anterior margin with short to long setae; ischium, small and subrectangular, anterior margin with 3 setae; merus, margins weakly setose, facial margin with 4 rows of stout setae: 5-3-7-5; carpus, facial margin with 4 rows of stout setae: 4-5-6-4; propodus, margins weakly setose, anterior margin with 6 stout setae, posterior margin with 7 stout setae; dactylus, about $40 \%$ the length of propodus. Pereopod 7 (Fig. 4C), coxa, subtriangular, posterior margin with short setae; basis, about $1.2 \times$ longer than wide, strongly expanded posteroventrally, reaching apex of carpus, anterodistal corner with 1 stout seta, posterior margin serrate, with setules; ischium, small and subquadrate, anterior margin with 2 stout setae; merus, anterior margin with 7 stout setae, posterior margin with 1 stout seta distally; carpus, anterior margin with 7 stout setae, posterior margin with 4 stout setae distally; propodus, anterior margin with 6 stout setae, posterior margin with 7 stout setae; dacytlus, with accessory seta, about $65 \%$ the length of propodus.

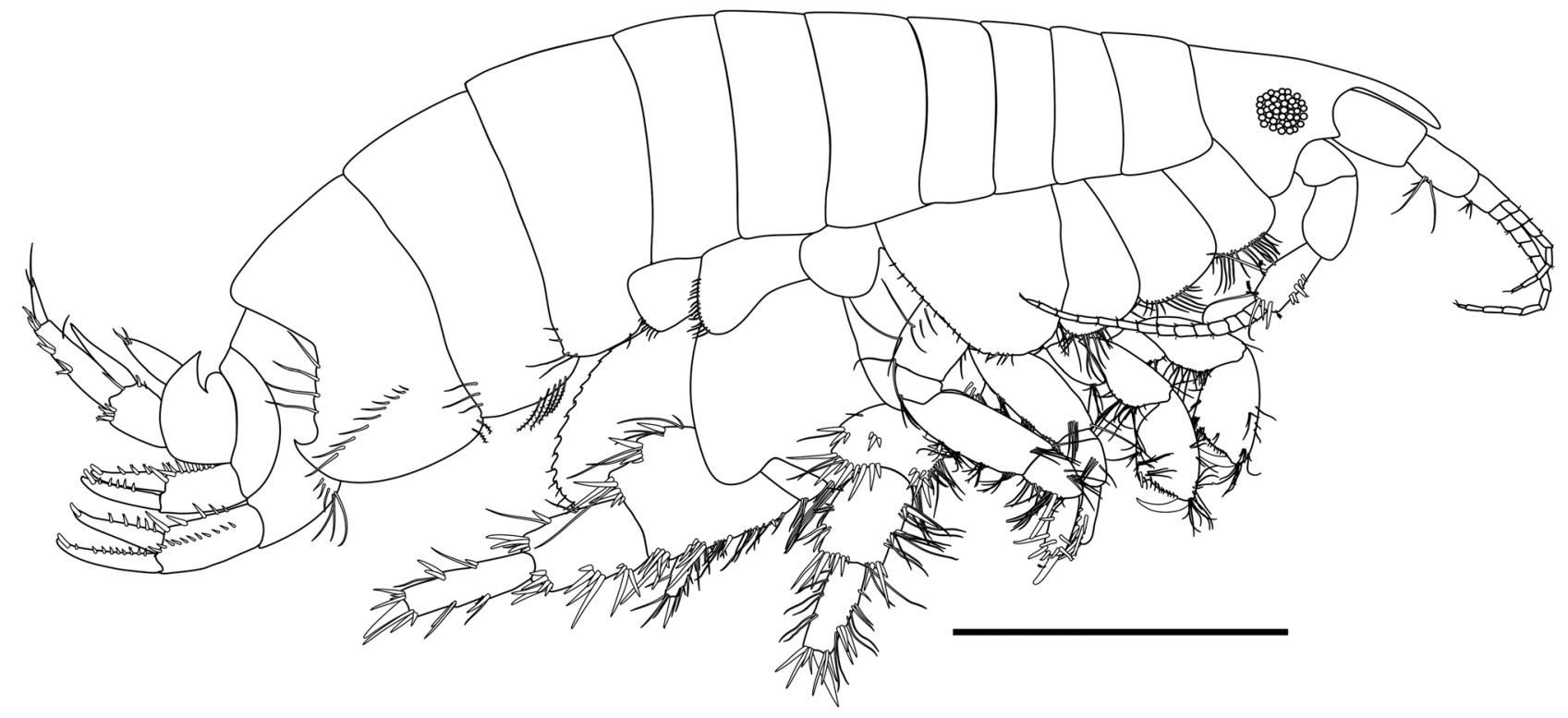

Figure 1. Metharpinia dentiurosoma Alonso de Pina, 2003, female (UERJ 409): Habitus. Scale bar: $1.5 \mathrm{~mm}$. 
Epimeral plate 1 (Fig. 5A), anterior margin rounded, anteroventral corner with 2 setae, posteroventral corner with a small rounded hump, bearing 2 long setae, posterior margin convex, with 2 short setae. Epimeral plate 2 (Fig. 5B), anterior margin weakly concave, with 2 setae, ventral margin with 5 plumose setae, posteroventral corner with a small subacute hump, posterior margin rounded, with 3 setae. Epimeral plate 3 (Fig. 5C),

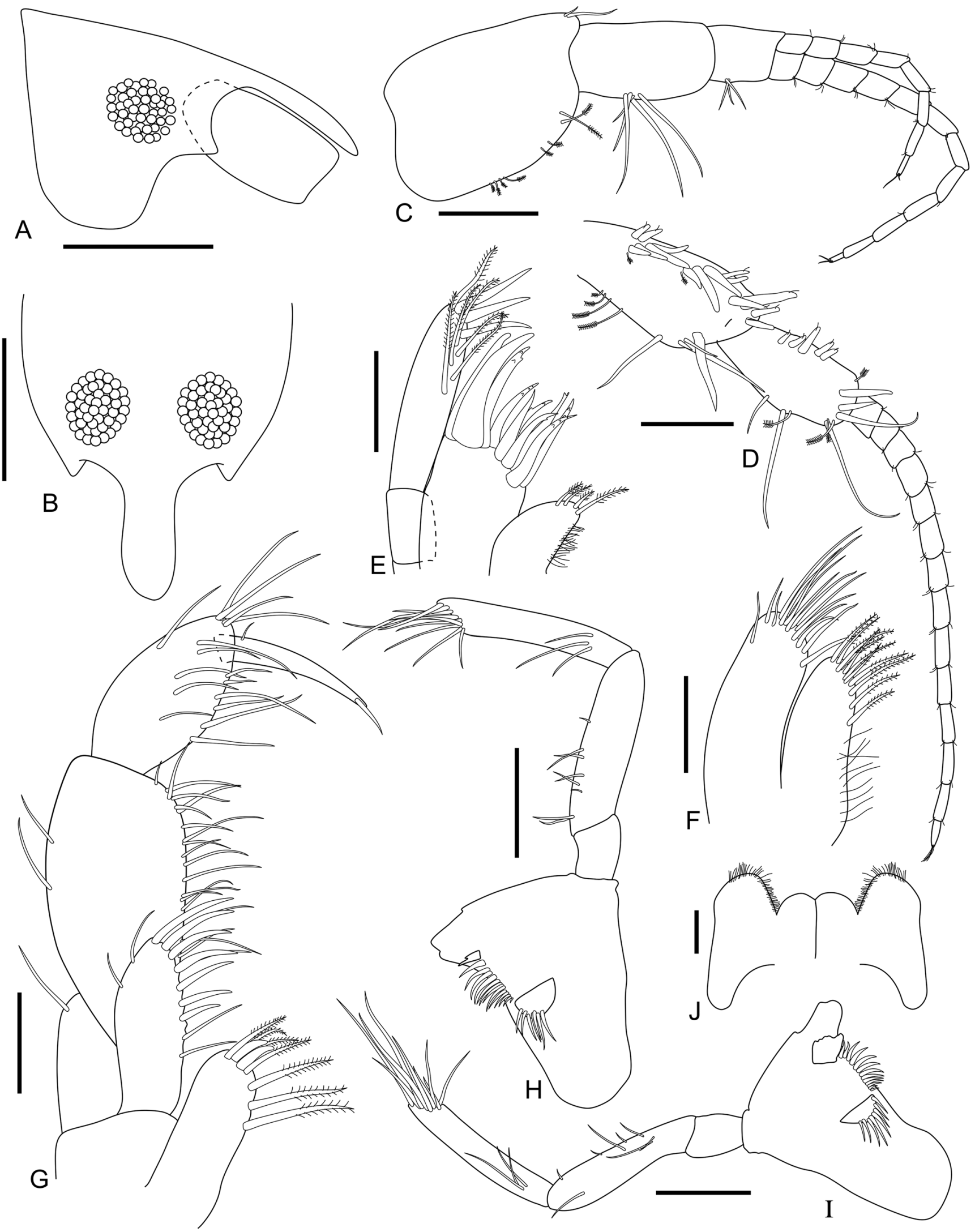

Figure 2. Metharpinia dentiurosoma Alonso de Pina, 2003, female (UERJ 409): (A) Head in lateral view; (B) Head in dorsal view; (C) Right antenna 1; (D) Right antenna 2; (E) Left maxilla 1; (F) Left maxilla 2; (G) Left maxilliped; (H) Right mandible; (I) Left mandible; (J) Lower lip. Scale bars: $0.5 \mathrm{~mm}$ for A-B; $0.2 \mathrm{~mm}$ for C-D, H-l; $0.1 \mathrm{~mm}$ for the remaining. 
anterior margin rounded, with 3 plumose setae, posteroventral corner strongly produced into a large tooth, posterior margin weakly crenulate, with 4 setae, facial margin with an oblique row of 10 stout setae extending from posteroventral margin to middle of plate, decreasing in length. Urosomite 3, produced as a large acute

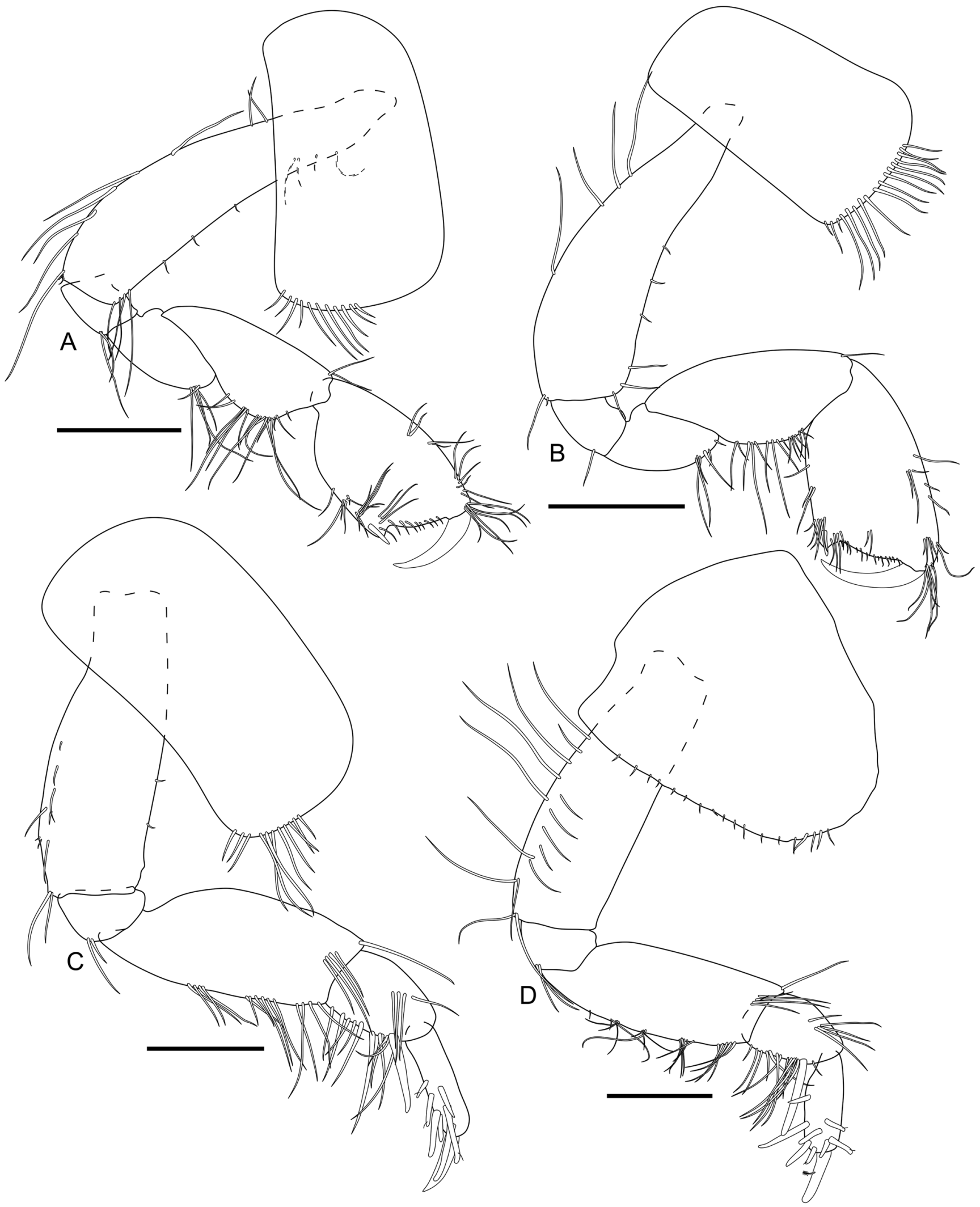

hook dorsally. Uropod 1 (Fig. 5D), peduncle, about 2.5x longer than wide, dorsomedial margin with 5 stout setae, dorsolateral margin with 11 stout setae, apicolateral corner microscopically combed; outer ramus, slightly longer than inner, dorsal margin with 9 stout setae, bearing 1 subapical nail; inner ramus, dorsal margin with 5 stout

Figure 3. Metharpinia dentiurosoma Alonso de Pina, 2003, female (UERJ 409): (A) Right gnathopod 1; (B) Right gnathopod 2; (C) Right pereopod 3; (D) Right pereopod 4. Scale bars: $0.3 \mathrm{~mm}$. 
setae, bearing 1 subapical nail. Uropod 2 (Fig. 5E), peduncle $2 \times$ longer than wide, dorsomedial margin with 10 stout setae, apicolateral corner microscopically combed; outer ramus, slightly longer than inner, dorsal margin with 5 stout setae, bearing 1 subapical nail; inner ramus,

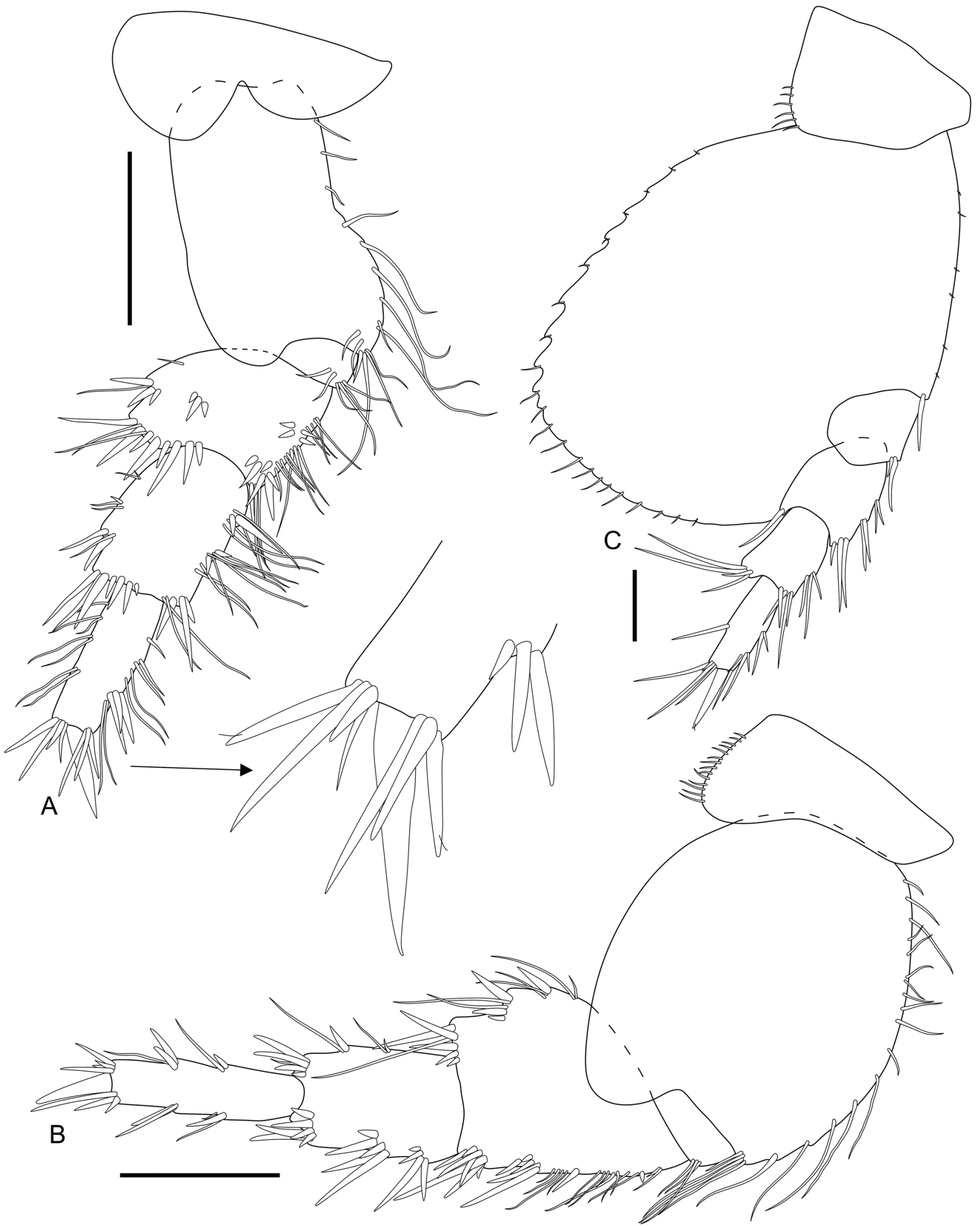

dorsal margin with 3 stout setae, bearing 1 subapical nail. Uropod 3 (Fig. 5F), peduncle, about $1.6 \times$ longer than wide, dorsal margin with 1 stout seta and 1 setule, ventral margin with 5 stout setae apically; outer ramus, article 1, ventral margin with 7 stout setae, article 2, elon- 
gate, with 2 setae apically; inner ramus, about $55 \%$ the length of outer, naked. Telson (Fig. 5G), about $85 \%$ cleft, apex subtruncate, with 1 plumose and 2 stout setae apically, lateral margins with 2 setae on each side.

Sexual dimorphism: Based on male (UERJ 411). Body, smaller in size. Eyes, larger and more pigmented.
Antenna 1 (Fig. 6B), peduncle article 1, 1.4× longer than wide, ventral margin with a tuft of setules and 3 brush setae distally, dorsal apex with 1 brush seta; article 2, ventral margin with 3 plumose setae medially and 4 setae distally; article 3, short, dorsal margin with 2 short and 2 brush setae; primary flagellum 10-articulate, with calceoli on articles 2-4; accessory flagellum 8-articulate. Antenna 2
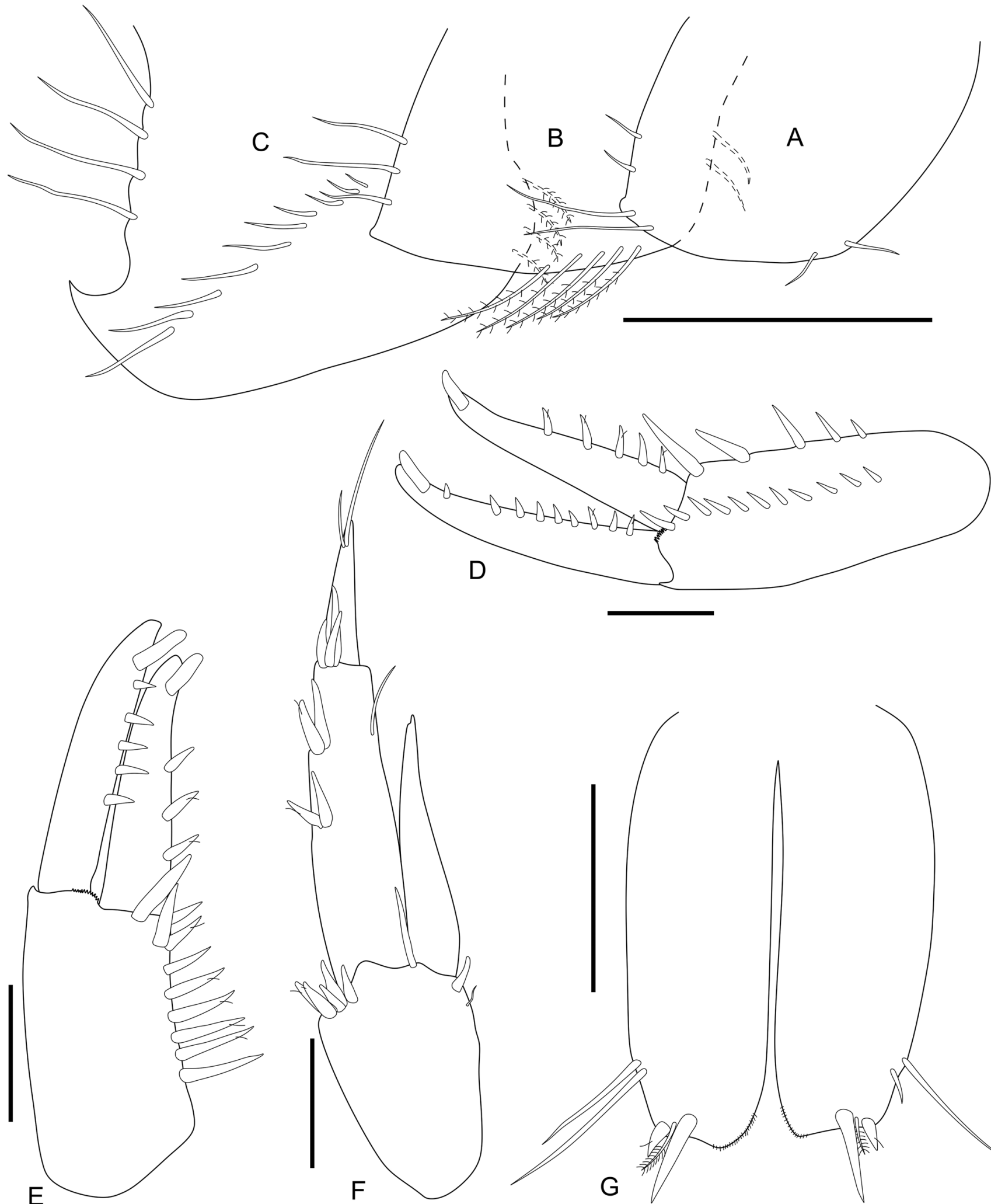
. 
(Fig. 6A), peduncle article 3, short, facial margin with 1 long seta, dorsal margin with a tuft of setules distally; article 4, facial stout setae formula: 1-2-4-3, ventral margin with 4 brush setae proximally, facial and ventral margin with long setae and 1 stout seta distally, dorsal margin covered with setules; article 5, facial margin with 3 stout setae and few brush setae, ventral margin with short to long setae and 4 brush setae, dorsal margin with tufts of setules; flagellum 32-articulate, with 11 calceoli.

Gnathopods 1-2 (Fig. 6C, D), similar in size, but more robust than in female.

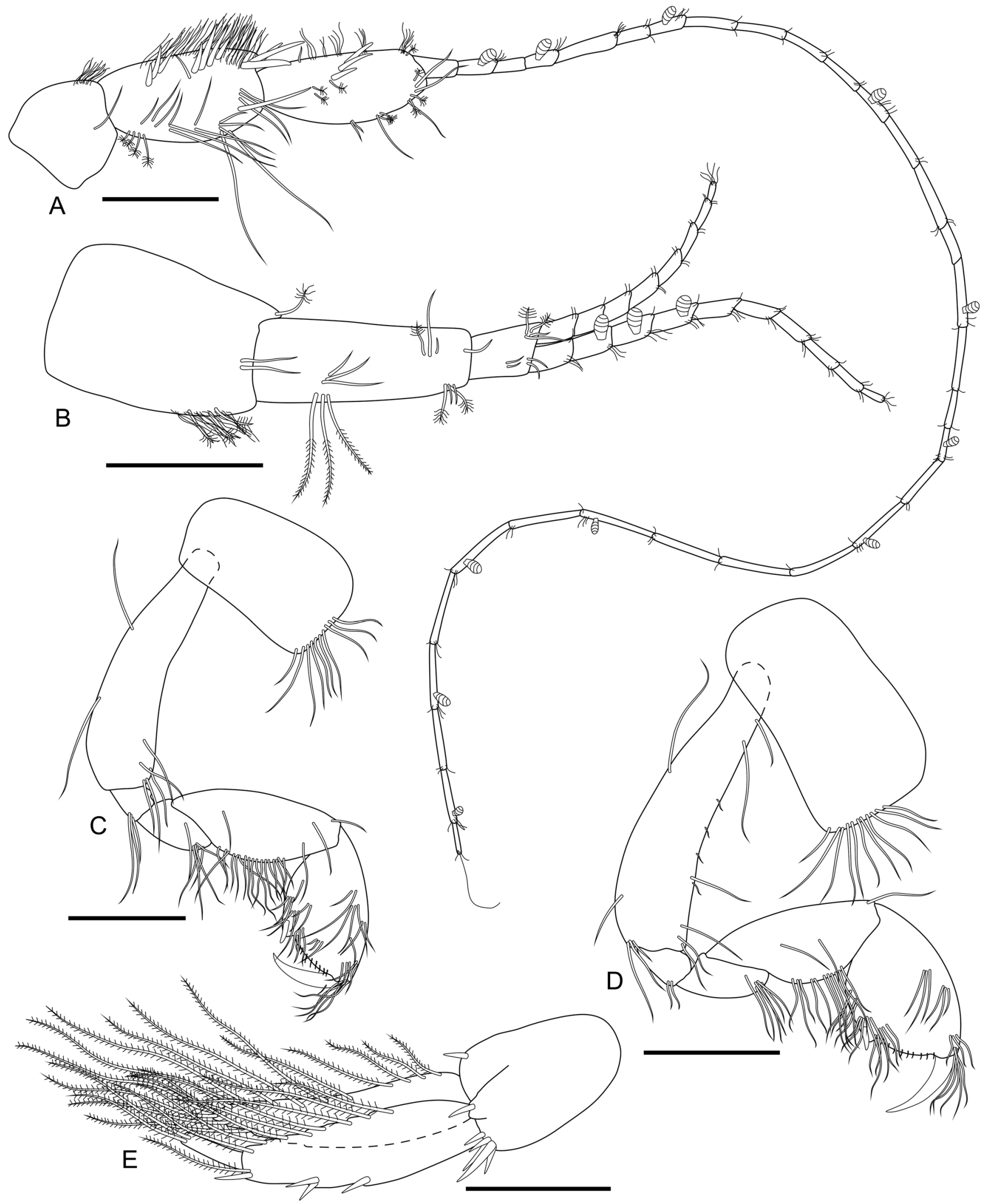

Figure 6. Metharpinia dentiurosoma Alonso de Pina, 2003, male (UERJ 411): (A) Right antenna 2; (B) Right antenna 1; (C) Right gnathopod 1; (D) Right gnathopod 2; (E) Right uropod 3. Scale bars: $0.2 \mathrm{~mm}$. 
Uropod 3 (Fig. 6E), peduncle, about $1.4 \times$ longer than wide, ventral margin with 5 stout setae distally, dorsal margin with 1 stout seta distally, lateral margin with a hump with 1 stout seta apically; outer ramus, article 1, ventral margin with 1 long plumose seta distally and two acclivities, stout setae formula: 1-2-1, dorsal margin with 7 long plumose setae, article 2, elongate, with 2 long plumose setae apically; inner ramus, slightly shorter than outer, dorsal margin covered with long plumose setae, apical margin with 2 long plumose setae.

Type locality: Argentine Sea, El Rincón, Buenos Aires, Argentina (39 $\left.49^{\prime} 58^{\prime \prime} \mathrm{S}, 61^{\circ} 35^{\prime} 02^{\prime \prime} \mathrm{W}\right)$.

Remarks: Metharpinia dentiurosoma was described with material from Buenos Aires (Argentina) and this is the first record of the species for Brazilian waters. Due to characteristics of antennae, mandibles, gnathopods and uropods, this species seems to be morphologically close to Mi. uroserratus described for Sepetiba Bay, Rio de Janeiro state, Brazil $\left(22^{\circ} 58^{\prime} \mathrm{S}, 44^{\circ} 02^{\prime} \mathrm{W}\right)$. However, it can be distinguished by the latter by presenting: head with a visible acute dorsolateral projection, rostrum slightly exceeding apex of first article of antenna 1; epimeral plate 3 posteroventral corner strongly produced into a large tooth and facial margin with an oblique row of stout setae.

Geographic distribution: Argentina: Argentine Sea; Brazil (this report): coast of the states of Rio de Janeiro, São Paulo and Santa Catarina.

Bathymetric range: 14-72 m depth.

\section{Metharpinia grandirama Alonso de Pina, 2003 (Figs. 7-11)}

Metharpinia grandirama Alonso de Pina, 2003b: 2533, figs. 8-15. López-Gappa et al., 2006: 16, 52. Alonso \& Chiesa, 2014: 206, 207, 209, fig. 3J-N. Andrade et al., 2015: 39.

Material examined: $1 \%$, in 70\% ethanol, MBT 217, $23^{\circ} 00^{\prime} \mathrm{S}, 42^{\circ} 41^{\prime} \mathrm{W}, 45 \mathrm{~m}$ depth, Rio de Janeiro state, 05 June 1971 (UERJ 421); 1 \%, in 70\% ethanol, MBT 90, $24^{\circ} 36^{\prime} \mathrm{S}, 4^{\circ} 07^{\prime} \mathrm{W}, 21 \mathrm{~m}$ depth, São Paulo state, 17 June 1970 (UERJ 422); 1 \%, dissected and drawn, MBT 81, $24^{\circ} 46^{\prime} \mathrm{S}, 45^{\circ} 58^{\prime} \mathrm{W}, 72 \mathrm{~m}$ depth, São Paulo state, 16 June 1970 (UERJ 419); 1 \%, in 70\% ethanol, MBT 172, 25²1'S, 47³0'W, 37 m depth, São Paulo state, 27 May 1971 (MZUSP 41106).

Diagnosis: Head, eyes rounded and medium-sized; rostrum constricted, narrow, elongate and spatulate. Antenna 1, peduncle article 2 elongate. Antenna 2, peduncle article 4, with 4 rows of facial stout setae. Mandible molar as a small hump with stout setae, lacinia mobilis flabellate; palp, article 3 longer than article 2. Maxilla 1, inner plate with 4 setae; palp 2-articulate. Maxilliped, inner plate with 2 stout setae apically; palp, article 4 narrow, with medium apical nail, partially embedded. Gnathopods 1-2, anterior margin weakly setose; palm acute, palmar hump large. Pereopod 7, basis, expanded posteroventrally, almost reaching apex of carpus. Epimeral plate 3, posteroventral corner rounded. Urosomite 3, produced as a large acute hook dorsally. Uropod 1, inner ramus, dorsal margin with 1 stout seta and 1 subapical nail. Uropod 2, short and stout; inner ramus short, with 1 subapical nail. Telson, deeply cleft, apex rounded, lateral margin with shallow acclivity, each lobe with 1 stout and variable simple and plumose setae.

Description: Based on female (UERJ 419). Habitus as in Fig. 7. Head (Fig. 8A, B), eyes rounded and medium-sized; rostrum constricted, narrow, elongate and spatulate. Antenna 1 (Fig. $8 \mathrm{C}$ ), peduncle article 1, about $1.4 \times$ longer than wide, ventral margin with 2 brush setae, dorsal apex with 1 seta; article 2, ventral margin with a tuft of plumose setae; article 3, short, ventral margin with 1 setule; primary flagellum 14-articulate; accessory flagellum 12-articulate. Antenna 2 (Fig. 8D), peduncle article 4, facial stout setae formula: $1-3-5-5$, ventral margin with medium to long plumose setae; dorsal margin with 1 stout and 1 plumose seta proximally; article 5, ventral margin with medium to long plumose setae, facial margin with row of 4 stout setae; flagellum 17-articulate. Left mandible (Fig. $8 \mathrm{H}$ ), molar as a small hump with 5 stout setae, incisor with 2 weak teeth and hump, lacinia mobilis flabellate, with 5 teeth, accessory setal row with 8 stout setae, palpar hump small; palp 3-articulate, article 1 short, article 2 with 2 setae, article 3 longer than article 2, apex oblique, with 9 medium to long setae. Right mandible (Fig. 8I), molar as a small hump with 6 stout setae, lacinia mobilis flabellate, incisor with 3 weak teeth, accessory setal setal row with 8 stout setae, palpar hump small; palp 3-articulate, article 1 short, article 2 with 2 setae, article 3 longer than article 2, apex oblique, with 11 medium to long setae. Maxilla 1 (Fig. 8F), inner plate with 4 setae; outer plate with with 9 multicuspidate stout setae; palp 2-articulate, article 2 with 4 simple setae and 3 pectinate stout setae apically. Maxilla 2 (Fig. 8E), inner plate, about $70 \%$ the length of outer, medial margin covered with setules, apical and subapical margins with simple and stout setae; outer plate, apical margin with plumose setae, lateral margin covered with setules. Maxilliped (Fig. 8G), inner plate with 6 plumose setae and 2 stout setae apically; outer plate with 7 bipectinate stout setae; palp, article 1 with 1 apicolateral seta, article 2, medial margin moderately setose, lateral margin with 5 long setae, article 3 , margins weakly setose, article 4, narrow, with accessory setule and 1 medium apical nail partially embedded, shorter than in M. dentiurosoma.

Gnathopod 1 (Fig. 9A), coxa, weakly expanded anteriorly, posterior margin weakly concave, ventral margin with 15 setae; basis, anterior and posterior margins with medium to long plumose setae; ischium, small and subrectangular, posterior margin with 4 long plumose setae; merus, posterior margin with 4 long plumose setae; carpus, anterior margin with 1 plumose seta distally, 
posterior margin moderately setose, facial margin with 4 long plumose setae; propodus, weakly setose, anterior margin with a tuft of setae, posterior margin with 1 stout seta defining palm; palm acute, with setules, palmar hump large; dactylus reaching the palmar corner. Gnathopod 2 (Fig. 9B), coxa, subrectangular, posterior margin weakly concave, ventral margin with 14 setae; basis, anterior and posterior margins with long plumose setae; ischium, small and subrectangular, posterodistal corner with 4 long plumose setae; merus, posterior margin with 3 short setae distally; carpus, anterior margin with row of 4 setae, posterior margin moderately setose; propodus, weakly setose, anterior margin with a tuft of setae, posterior margin with 1 stout seta defining palm; palm acute, with setules, palmar hump large; dactylus, reaching the palmar corner. Pereopod 3 (Fig. 9C), coxa subrectangular, proportionally shorter than in $M$. dentiurosoma, ventral margin with 17 setae; basis, posterior margin with medium to long setae; ischium, small and subrectangular, posterodistal corner with 4 short setae; merus, anterior margin with 1 seta distally, posterior margin moderately setose; carpus, posterior margin weakly setose, with 1 subdistal thicker stout setae extending $75 \%$ of propodus; propodus, anterior margin with 1 short plumose seta distally, posterior margin with 11 stout setae; dactylus, about $50 \%$ the length or propodus. Pereopod 4 (Fig. 9D), coxa, posteroventral margin setose; remaining articles are very similar to pereopod 3, differing only by some arrangements of setae. Pereopod 5 (Fig. 10A), coxa, bilobate, posteroventral margin with 13 setae; basis subrectangular and thickening distally, anterior margin weakly setose, anterodistal corner with 3 setae and row of 6 setae extending to facial margin; ischium, small and subrectangular, anterodistal corner with row of 6 setae; merus, anterior and posterior margins setose, facial stout setae formula: 6-5-6-4-6; carpus more robust than in $M$. dentiurosoma, anterior and posterior margins moderately setose, facial stout setae formula: 3-8-5-7-6; propodus, anterior and posterior margins moderately setose, anterior margin with 7 stout setae, posterior margin with 2 stout setae; dactylus, about $45 \%$ the length of propodus. Pereopod 6 (Fig. 10B), coxa, posterior margin with 3 setae; basis weakly setose, posterior margin more straight than in $M$. dentiurosoma anterodistal corner with a tuft of setae; ischium, small and subrectangular, anterodistal corner with a row of 6 setae; merus, anterior margin with long and stout setae, posterior margin with long bipectinate and stout setae, facial stout setae formula: 4-6-5-8; carpus, posterior margin with long setae, facial stout setae formula: 8-4-6-3; propodus, posterior margin with long setae, facial stout setae formula: 3-2-3-2-3; dactylus, short, about 20\% the length of propodus. Pereopod 7 (Fig. 10C), coxa, subrectangular, posterior margin with 9 setae; basis, $1.5 \times$ longer than wide, expanded posteroventrally, reaching half of carpus, posterior margin weakly crenulate, anterodistal corner with 1 seta; ischium, small and subquadrate, anterior margin with 2 setae; merus, anterior and posterior margins with 4 setae; carpus, anterior margin with 8 setae, posterior margin with row of 4 setae distally; propodus, anterior and posterior margins weakly setose; dactylus, about $70 \%$ the length of propodus.

Epimeral plate 1 (Fig. 11A), anterior margin with 4 setae, ventral margin with 8 plumose setae, posterior margin convex, weakly serrate, with 5 setae. Epimeral plate 2 (Fig. 11B), anterior margin produced and rounded, ventral margin with 8 plumose setae, posterior margin weakly crenulate, with 3 setae. Epimeral plate $\mathbf{3}$ (Fig. 11C), anterior margin produced and rounded, pos-

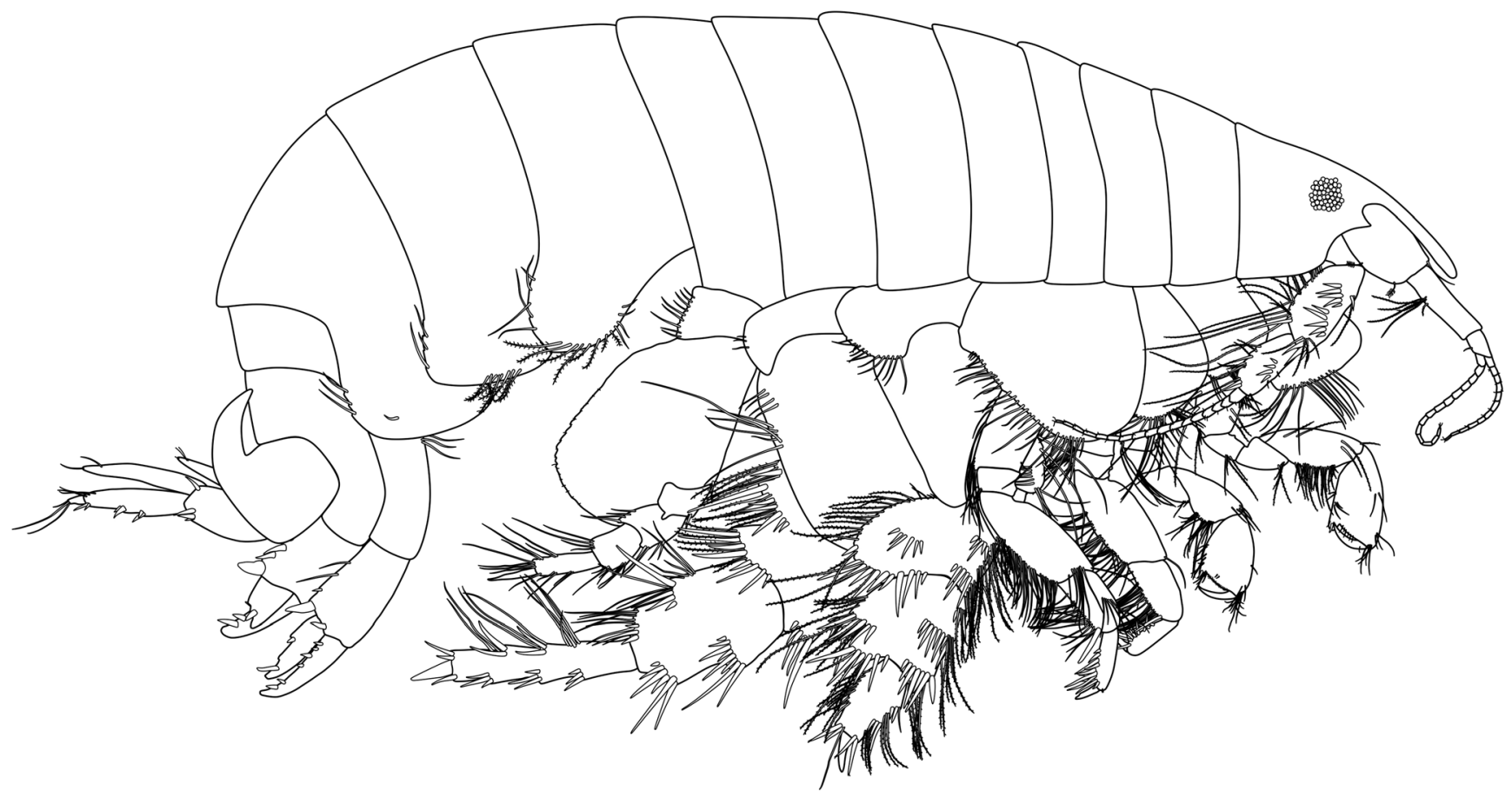

Figure 7. Metharpinia grandirama Alonso de Pina, 2003, female (UERJ 419): Habitus. Scale bar: $2.5 \mathrm{~mm}$. 
teroventral corner rounded, posterior margin weakly crenulate, with 3 setae, facial margin with 1 short seta. Urosomite 1, ventral margin with a proximal tuft of se- tae. Urosomite 3, produced as a large acute hook dorsally. Uropod 1 (Fig. 11D), peduncle, about $1.7 \times$ longer than wide, dorsomedial margin with 2 long and 1 short stout

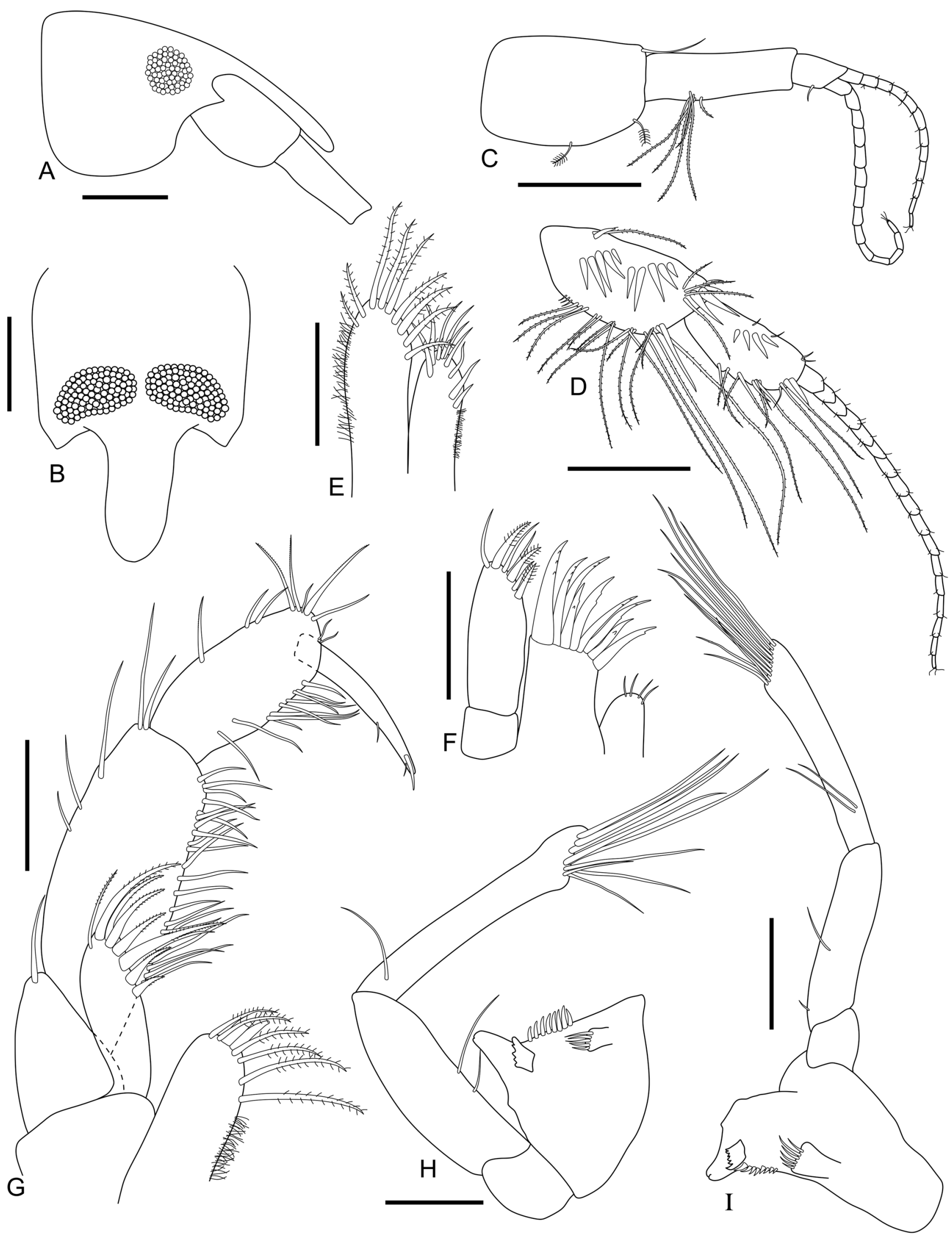

Figure 8. Metharpinia grandirama Alonso de Pina, 2003, female (UERJ 419): (A) Head in lateral view; (B) Head in dorsal view; (C) Right antenna 1; (D) Right antenna 2; (E) Left maxilla 2; (F) Left maxilla 1; (G) Left maxilliped; (H) Left mandible; (I) Right mandible. Scale bars: $0.5 \mathrm{~mm}$ for A-D; $0.1 \mathrm{~mm}$ for E; $0.2 \mathrm{~mm}$ for the remaining. 
seta, dorsomedial corner with 1 thicker stout seta, dorsolateral corner with 1 stout seta; rami shorter than peduncle; outer ramus, slightly longer than inner, dorsal margin with 5 stout setae bearing 1 subapical nail; inner ramus, dorsal margin with 1 stout seta, bearing 1 subapical nail.
Uropod 2 (Fig. 11E), short and stout, peduncle, about $1.4 \times$ longer than wide, dorsolateral margin with 6 stout setae, being the apical-most much stouter; rami shorter than peduncle; outer ramus, $1.6 \times$ longer than inner, dorsal margin with 4 stout setae, bearing 1 subapical nail;

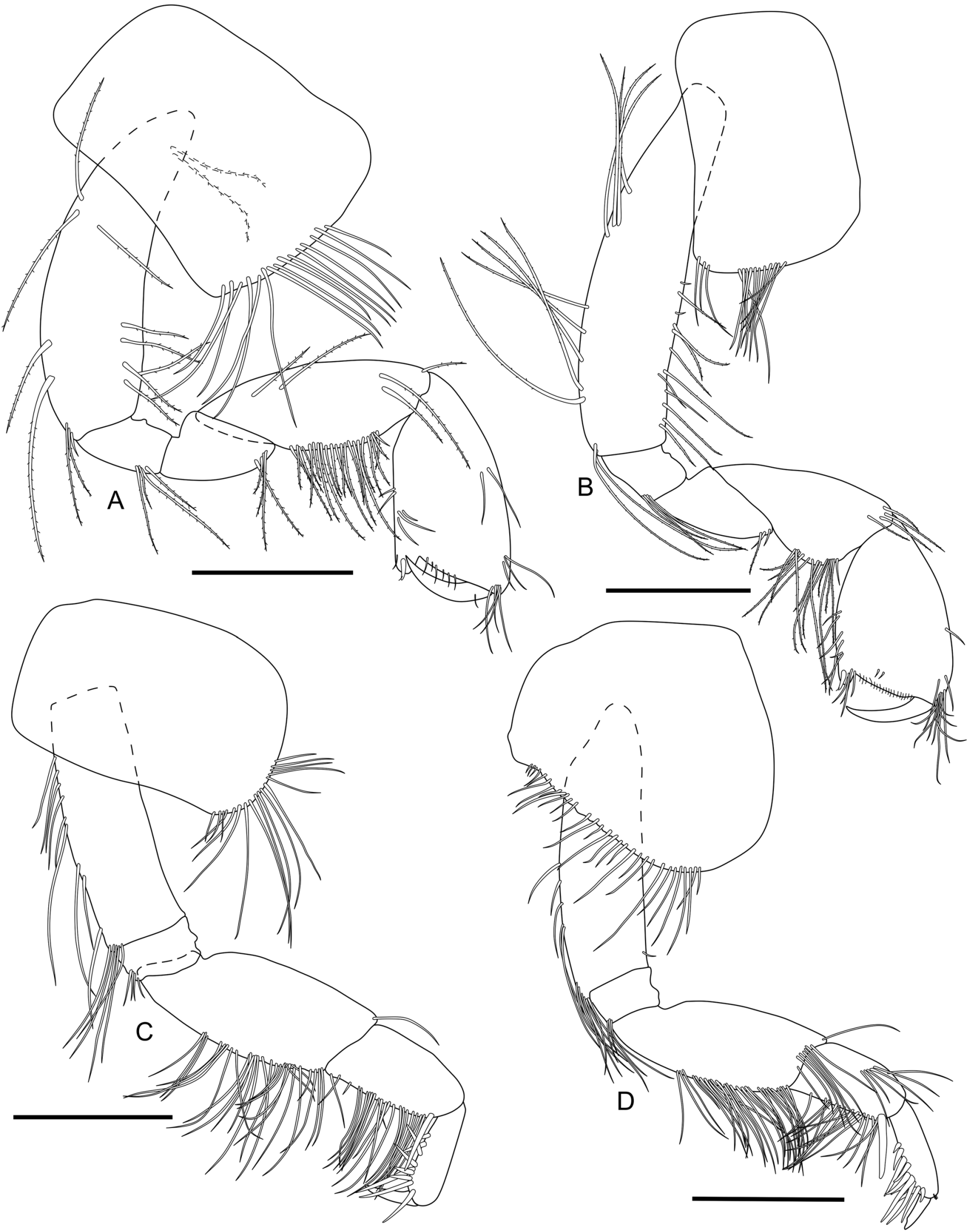

Figure 9. Metharpinia grandirama Alonso de Pina, 2003, female (UERJ 419): (A) Right gnathopod 1; (B) Right gnathopod 2; (C) Right pereopod 3; (D) Right pereopod 4. Scale bars: $0.5 \mathrm{~mm}$. 
inner ramus, short, bearing 1 subapical nail. Uropod 3 (Fig. 11F), peduncle, about $2 \times$ longer than wide, ventral margin with 3 stout setae, dorsal margin with 1 stout seta; outer ramus, slightly longer than inner, article 1, ventral margin with 2 acclivities, stout setae formula: 2-2-2, dorsal margin with 3 setae distally, article 2, short, with 1 short and 2 long setae apically; inner ramus, with 1 apical and 1 subapical seta. Telson (Fig. 11G), about $80 \%$ cleft, apex rounded on the inner part, with shallow lateral acclivity, with 1 short stout and 2 plumose setae on each side, dorsolateral margin with 1 plumose and 3 long setae on each side.

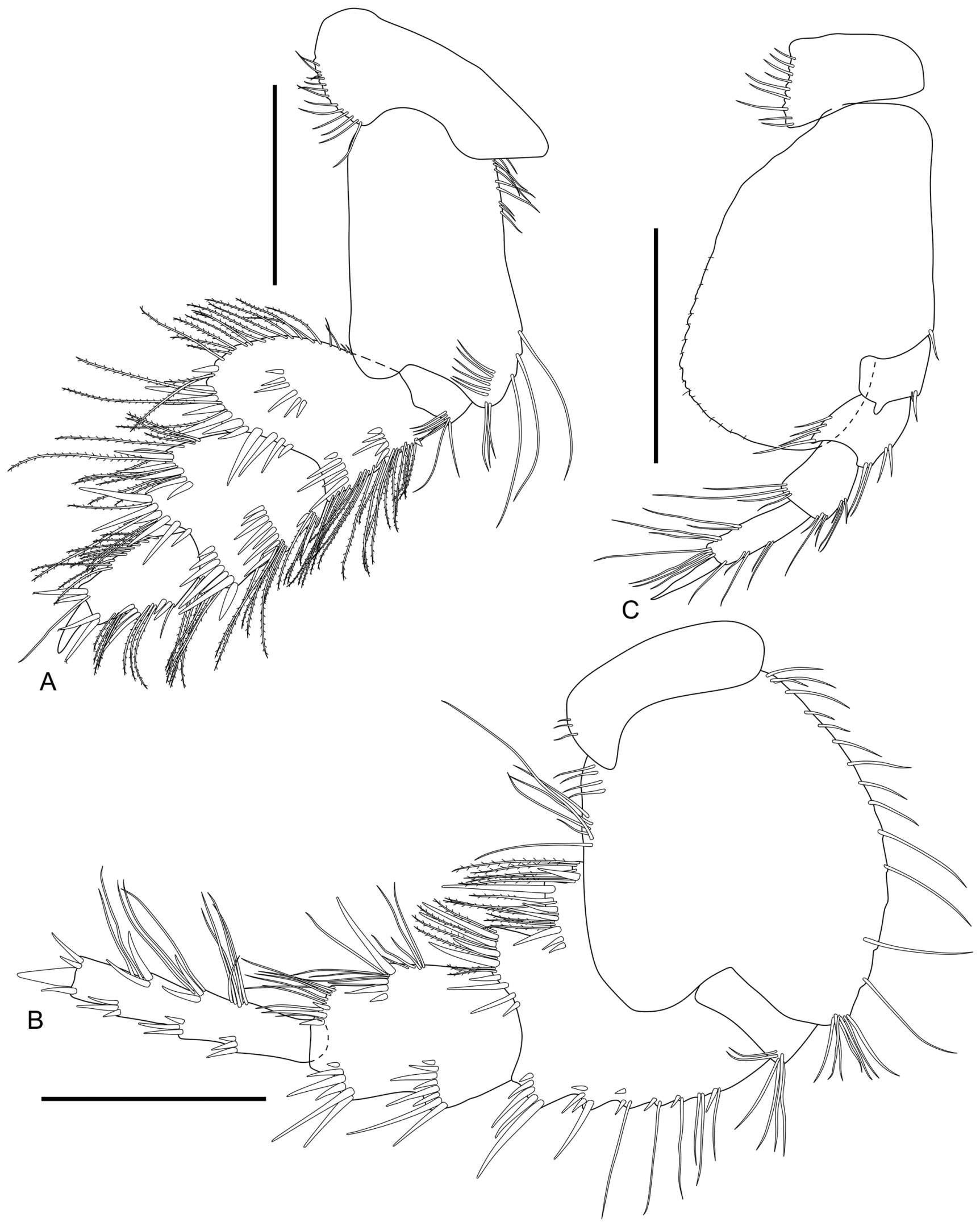

Figure 10. Metharpinia grandirama Alonso de Pina, 2003, female (UERJ 419): (A) Right pereopod 5; (B) Right pereopod 6; (C) Right pereopod 7. Scale bars: $1.0 \mathrm{~mm}$. 
Type locality: Argentine Sea, El Rincón, Buenos Aires, Argentina $\left(39^{\circ} 05^{\prime} 36^{\prime \prime} \mathrm{S}, 61^{\circ} 20^{\prime} 11^{\prime \prime} \mathrm{W}\right)$.

Remarks: Metharpinia grandirama was described with material from Buenos Aires (Argentina) and this is the first record of the species for Brazilian waters. Due to characteristics of antennae, gnathopods and especially the shape of uropods 1-2, this species seems to be morphologically very close to Mi. breviramus, described for Arraial do Cabo, Rio de Janeiro state, Brazil $\left(23^{\circ} 03^{\prime} S\right.$,

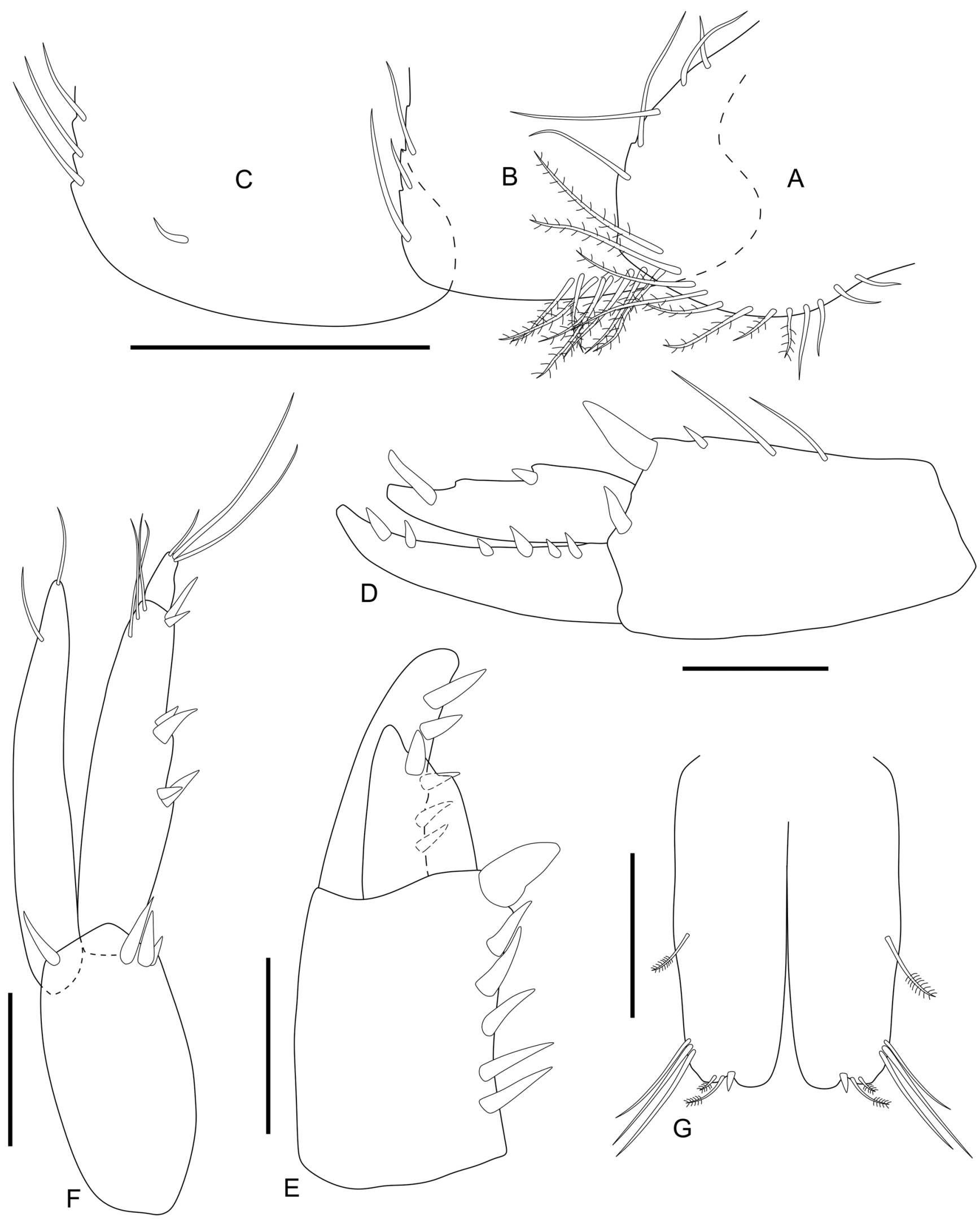

Figure 11. Metharpinia grandirama Alonso de Pina, 2003, female (UERJ 419): (A) Right epimeral plate 1; (B) Right epimeral plate 2; (C) Right epimeral plate 3; (D) Right uropod 1; (E) Right uropod 2; (F) Right uropod 3; (G) Telson. Scale bars: $0.5 \mathrm{~mm}$ for A-C; $0.2 \mathrm{~mm}$ for the remaining. 
$42^{\circ} 02^{\prime} \mathrm{W}$ ), with both presenting rami of uropods $1-2$ much shorter than the other species of their respective genus. However, M. grandirama can be distinguished by the latter by subtle characteristics like: head with a visible dorsolateral projection; pereopod 7, basis not so expanded posteriorly; setal distribution on epimeral plates 1-3; and number of stout setae on uropods 1-2. Even if morphological variations are reported for different individuals of both species, due to the strong similarities on their uropods, a new analysis of the type material used for the original descriptions is necessary in order to confirm if both species are valid or if they should be synonymized.

Geographic distribution: Argentina: Argentine Sea; Brazil: coast of the states of Rio de Janeiro and São Paulo.

Bathymetric range: 9-72 $\mathrm{m}$ depth.

\section{Metharpinia iado Alonso de Pina, 2003 (Figs. 12-17)}

Metharpinia iado Alonso de Pina, 2003a: 1031, figs. 1-9, 16. López-Gappa et al., 2006: 16, 52. De Broyer et al., 2007: 189. Alonso de Pina et al., 2008: 17-19, 33. Alonso \& Chiesa, 2014: 206, 207, 209, fig. 3Q-T. Andrade et al., 2015: 39.

Material examined: 1 , dissected and drawn, MBT 129, $29^{\circ} 13^{\prime} \mathrm{S}, 49^{\circ} 25^{\prime} \mathrm{W}, 27 \mathrm{~m}$ depth, Santa Catarina state, 25 June 1970 (UERJ 423); $10^{*}$, dissected and drawn, MBT $129,29^{\circ} 13^{\prime} \mathrm{S}, 49^{\circ} 25^{\prime} \mathrm{W}, 27 \mathrm{~m}$ depth, Santa Catarina state, 25 June 1970 (UERJ 424); 24 \%ᄋ, in 70\% ethanol, MBT 129, $29^{\circ} 13^{\prime} \mathrm{S}, 49^{\circ} 25^{\prime} \mathrm{W}, 27 \mathrm{~m}$ depth, Santa Catarina state, 25 June 1970 (UERJ 425); 24 \%क, in 70\% ethanol, MBT 129, $29^{\circ} 13^{\prime} \mathrm{S}, 49^{\circ} 25^{\prime} \mathrm{W}, 27 \mathrm{~m}$ depth, Santa Catarina state, 25 June 1970 (MZUSP 41107).

Diagnosis: Head, eyes rounded and medium-sized; rostrum constricted, narrow, elongate, spatulate. Antenna 1 , peduncle article 2 elongate. Antenna 2, peduncle article 4 , with 4 rows of stout setae. Mandible molar, as a small hump with stout setae, lacinia mobilis flabellate (left) or simple (right); palp, article 3 longer than article 2. Maxilliped, inner plate with 1 stout seta apically; palp, article 4 narrow, with medium apical nail, partially embedded. Gnathopods 1-2, anterior margin weakly setose; palm acute, palmar hump small. Pereopod 7, basis, expanded posteroventrally, reaching apex of carpus. Epimeral plate 3, posteroventral corner rounded, posterior margin weakly crenulate. Urosomite 1, ventral margin with a proximal tuft of setae. Urosomite 3, not produced dorsally into a hook. Uropods 1-2, outer ramus, with row of stout setae continuously to apex. Uropod 3, outer ramus, article 2, elongate, with 2 apical setae; inner ramus with plumose setae. Telson long, deeply cleft, apex obliquely truncate with inner corner produced into a tooth, with stout and plumose setae, dorsolateral margin with long setae.
Description: Based on female (UERJ 423). Habitus as in Fig. 12A. Head (Fig. 13A, B), eyes rounded and medium-sized; rostrum, constricted, narrow, elongate and spatulate. Antenna 1 (Fig. 13C), peduncle article 1, about $1.4 \times$ longer than wide, ventral margin with 3 plumose setae, dorsal apex with 1 long seta; article 2, ventral margin with row of long plumose setae medially; article 3, short, ventral margin with 2 plumose setae; primary flagellum 11-articulate; accessory flagellum 9-articulate. Antenna 2 (Fig. 13D), peduncle article 4, facial stout setae formula: 1-3-6-5, ventral margin with short to long plumose setae, dorsal margin with 1 stout and long plumose setae medially and distally; article 5, ventral margin with short to long plumose setae, dorsal margin weakly setose, facial margin with 5 stout setae; flagellum 14-articulate. Left mandible (Fig. 13H), molar as a small hump with 5 stout setae, incisor with 3 teeth, lacinia mobilis flabellate, with 5 teeth, accessory setal row with 12 stout setae, palpar hump small; palp 3-articulate, article 1 short, article 2, with 5 medium to long setae, article 3 slightly longer than article 2, apex oblique, with 11 medium to long setae. Right mandible (Fig. 13I), molar as a small hump with 5 stout setae, incisor with 3 teeth, lacinia mobilis simple, accessory setal row with 11 stout setae, palpar hump small; palp 3-articulate, article 1 short, article 2, with 5 medium to long setae, article 3 slightly longer than article 2, apex oblique, with 13 medium to long setae. Maxilla 1 (Fig. 13E), inner plate with 2 plumose and 2 simple setae; outer plate with 11 multicuspidate stout setae; palp 2-articulate, article 2, with 5 simple and 7 plumose setae. Maxilla 2 (Fig. 13F), inner plate, slightly shorter than outer, medial margin with row of setules and 3 plumose setae, apical and subapical margins with 6 setae; outer plate, lateral margin covered with setules, apical and subapical margins setose. Maxilliped (Fig. 13G), inner plate with 1 stout seta apically and 11 plumose setae; outer plate with 7 pectinate stout setae; palp, article 1 with 4 apicolateral setae, article 2, lateral margin with 7 setae, medial margin moderately setose, article 3, margins moderately setose, article 4, narrow, with medium apical nail, partially embedded.

Gnathopod 1 (Fig. 14A), coxa, subrectangular, ventral margin almost straight, with 20 setae; basis, anterior margin with short to long setae, posterodistal corner with 3 setae; ischium, small and subrectangular, posterodistal corner with 3 setae; merus, posterior margin with 6 setae; carpus, anterior margin with 1 short seta distally, posterior margin moderately setose; propodus, weakly setose, anterior margin with a tuft of setae, posterior margin with 1 stout seta defining palm; palm acute, with setules, palmar hump small; dactylus reaching the palmar corner. Gnathopod 2 (Fig. 14B), coxa, subrectangular, ventral margin almost straight, with 18 setae; basis, anterior and posterior margins with 4 setae; ischium, small and subrectangular, posterior margin with 3 setae; merus, posterior margin with 4 setae; carpus, posterior margin moderately setose; propodus, weakly setose, anterior margin with a tuft of setae, posterior margin with 1 stout seta defining palm; palm 
acute, with setules, palmar hump small; dactylus slightly longer than palm. Pereopod 3 (Fig. 14C), coxa, subrectangular, ventral margin with 13 setae; basis, posterior margin with 5 setae; ischium, small and subrectangular, posterior margin with 4 setae; merus, anterior margin with 1 seta distally, posterior margin moderately setose, facial margin with row of 5 setae distally; carpus, posterior margin moderately setose, with 1 subdistal thicker stout seta, extending $70 \%$ of propodus, facial margin with row of long setae; propodus, anterior margin with 7 stout setae, posterior margin with 6 stout setae; dactylus, about $30 \%$ the length of propodus, inner margin with an acute tooth distally. Pereopod 4 (Fig. 14D), coxa elliptico-rectangular, posterodorsal margin weakly excavate, posteroventral margin with 13 setae; remaining articles are very similar to pereopod 3, differing only by some arrangements of setae. Pereopod 5 (Fig. 15A), coxa bilobate, posterior margin with 15 plumose setae; basis, anterior margin with short to long pectinate setae, anterodistal corner with row of pectinate setae extending to facial margin; ischium, small and subrect- angular, anterior margin with 5 setae; merus more robust than in $M$. dentiurosoma, anterior margin with long pectinate setae, posterior margin moderately setose, facial margin with dense rows of stout setae; carpus more robust than in $M$. dentiurosoma, anterior and posterior margins with long pectinate setae, facial stout setae formula: 4-7-7-7-12; propodus, anterior and posterior margins moderately setose; dactylus, about $55 \%$ the length of propodus, inner margin with an acute tooth distally. Pereopod 6 (Fig. 15B), coxa, posteroventral margin with 18 setae; basis, anterior margin with medium to long pectinate setae; ischium, small and subrectangular, anterior margin with 4 setae; merus, anterior margin with stout and long setae, posterior margin with long plumose setae, facial stout setae formula: 3-8-8; carpus, anterior and posterior margins weakly setose, facial stout setae formula: 4-6-6-3; propodus, anterior and posterior margins weakly setose, facial margin with many sets of stout setae; dactylus, about 30\% the length of propodus, inner margin with an acute tooth distally. Pereopod 7 (Fig. 15C), coxa, ovatorectangular,
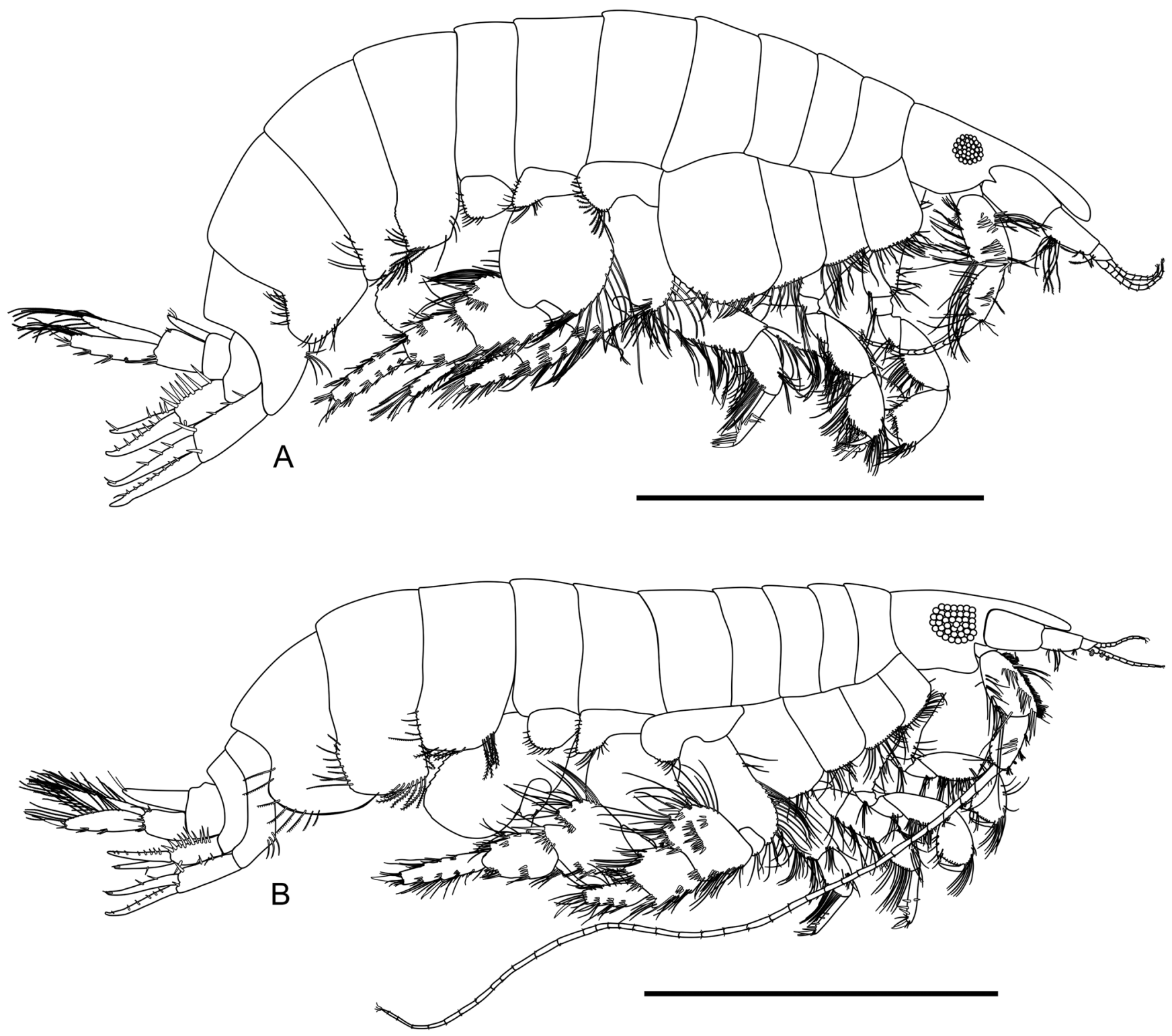

Figure 12. Metharpinia iado Alonso de Pina, 2003: (A) Habitus of female (UERJ 423); (B) Habitus of male (UERJ 424). Scale bars: $2.0 \mathrm{~mm}$. 
posteroventral margin wit 11 setae; basis, about $1.4 \times$ longer than wide, strongly expanded posteroventrally, reaching apex of carpus, posterior margin weakly serrate, anterodistal corner with 2 setae; ischium, subrectangular, anterodistal corner with 1 stout seta; merus, an- terior margin with 3 stout and 2 simple setae, posterior margin with 2 setae; carpus, anterior margin with stout setae, posterodistal corner with 3 long plumose setae; propodus, anterior and posterior margins weakly setose; dactylus, about $55 \%$ the length of propodus.
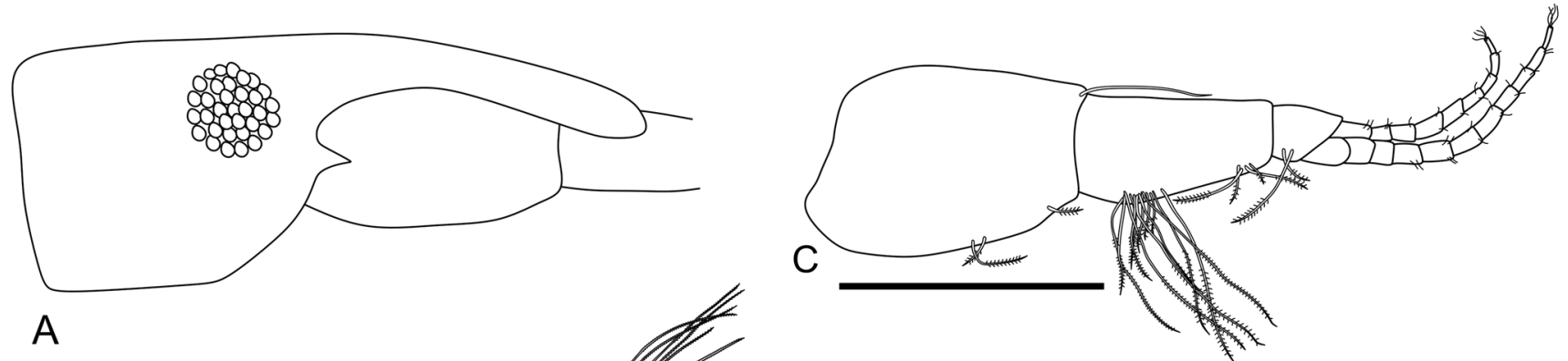

A
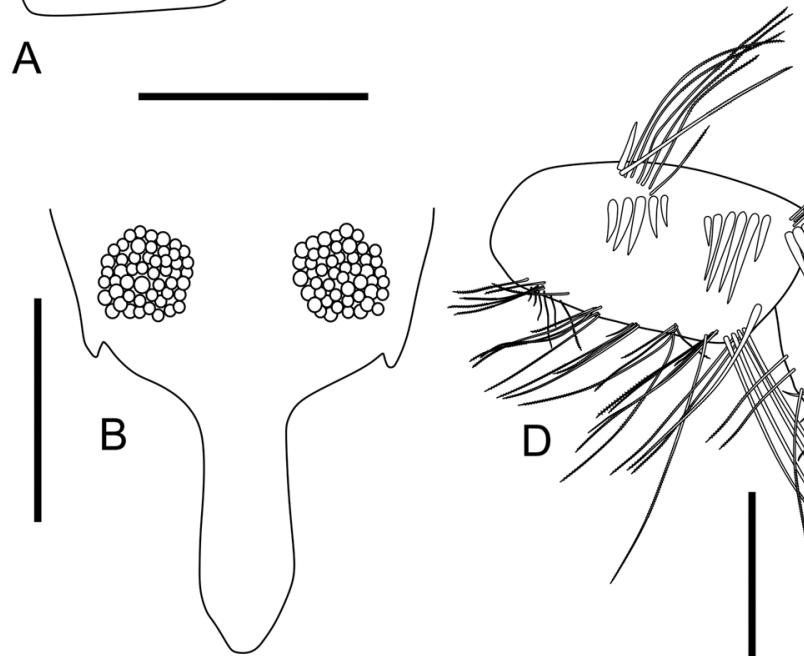

\section{$\mathrm{C}$}
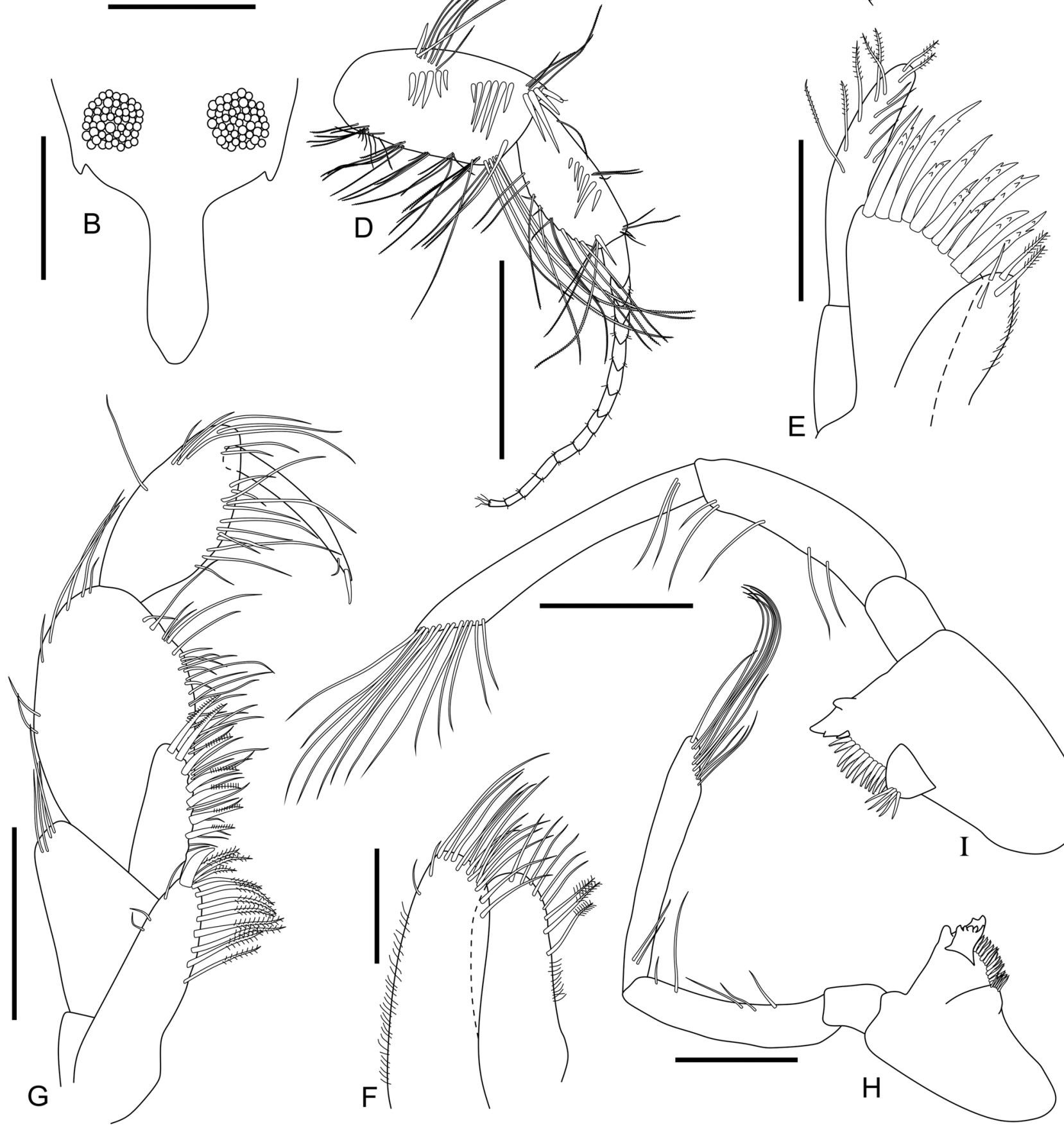

E

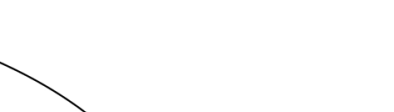

Figure 13. Metharpinia iado Alonso de Pina, 2003, female (UERJ 423): (A) Head in lateral view; (B) Head in dorsal view; (C) Right antenna 1; (D) Right antenna 2; (E) Left maxilla 1; (F) Left maxilla 2; (G) Left maxilliped; (H) Left mandible; (I) Right mandible. Scale bars: $0.5 \mathrm{~mm}$ for A-D; $0.1 \mathrm{~mm}$ for E-F; $0.2 \mathrm{~mm}$ for the remaining. 
Epimeral plate 1 (Fig. 16A), anterior margin with 3 setae, anteroventral corner subquadrate, ventral margin with 4 long plumose setae, posterior margin straight, crenulate to weakly serrate, with 4 pectinate setae. Epimeral plate 2 (Fig. 16B), anteroventral corner subquadrate, ventral margin with 8 long plumose setae, posterior margin straight,

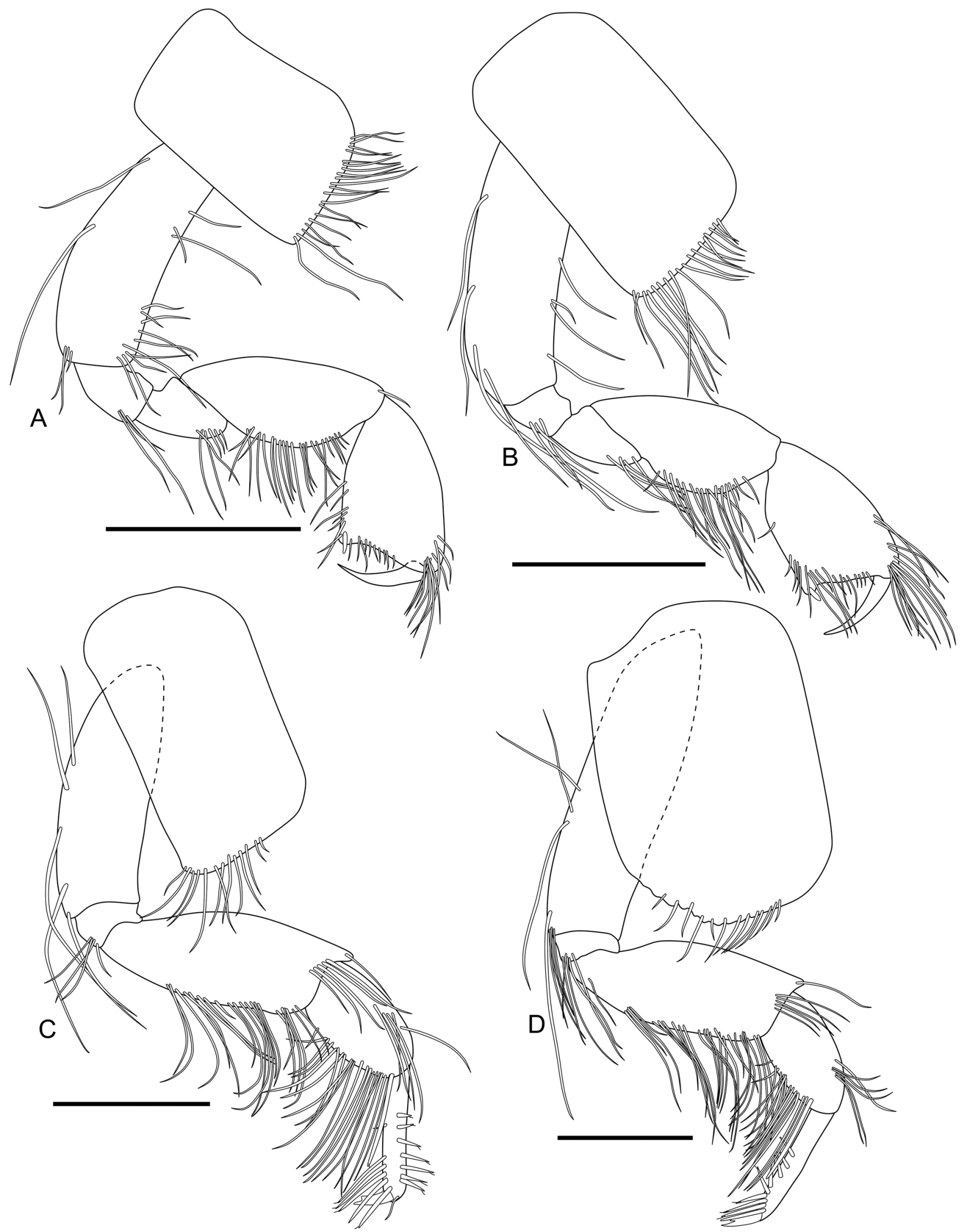

Figure 14. Metharpinia iado Alonso de Pina, 2003, female (UERJ 423): (A) Right gnathopod 1; (B) Right gnathopod 2; (C) Right pereopod 3; (D) Right pereopod 4. Scale bars: $0.5 \mathrm{~mm}$. 
weakly crenulate, with 6 pectinate setae. Epimeral plate 3 (Fig. 16C), anteroventral corner subquadrate, ventral margin with 7 setae, posteroventral corner rounded, posterior margin convex, crenulate, with 11 setae. Urosomite 1, ventral margin with a tuft of setae. Uropod 1 (Fig. 16D), peduncle, about $2.3 \times$ longer than wide, dorsomedial margin with 4 stout setae, dorsolateral margin with 1 stout seta apically; outer ramus, slightly longer than inner, dorsal margin with 8 stout setae, bearing 1 subapical nail; inner ramus, dorsal margin with 3 stout setae, bearing 1 subapical nail. Uropod 2 (Fig. 16E), peduncle, about $2.2 \times$ longer than wide, dorsomedial margin with 7 stout setae, ventrolateral margin with 1 stout seta apically; outer ramus, slightly longer than inner, dorsal margin with 6 stout

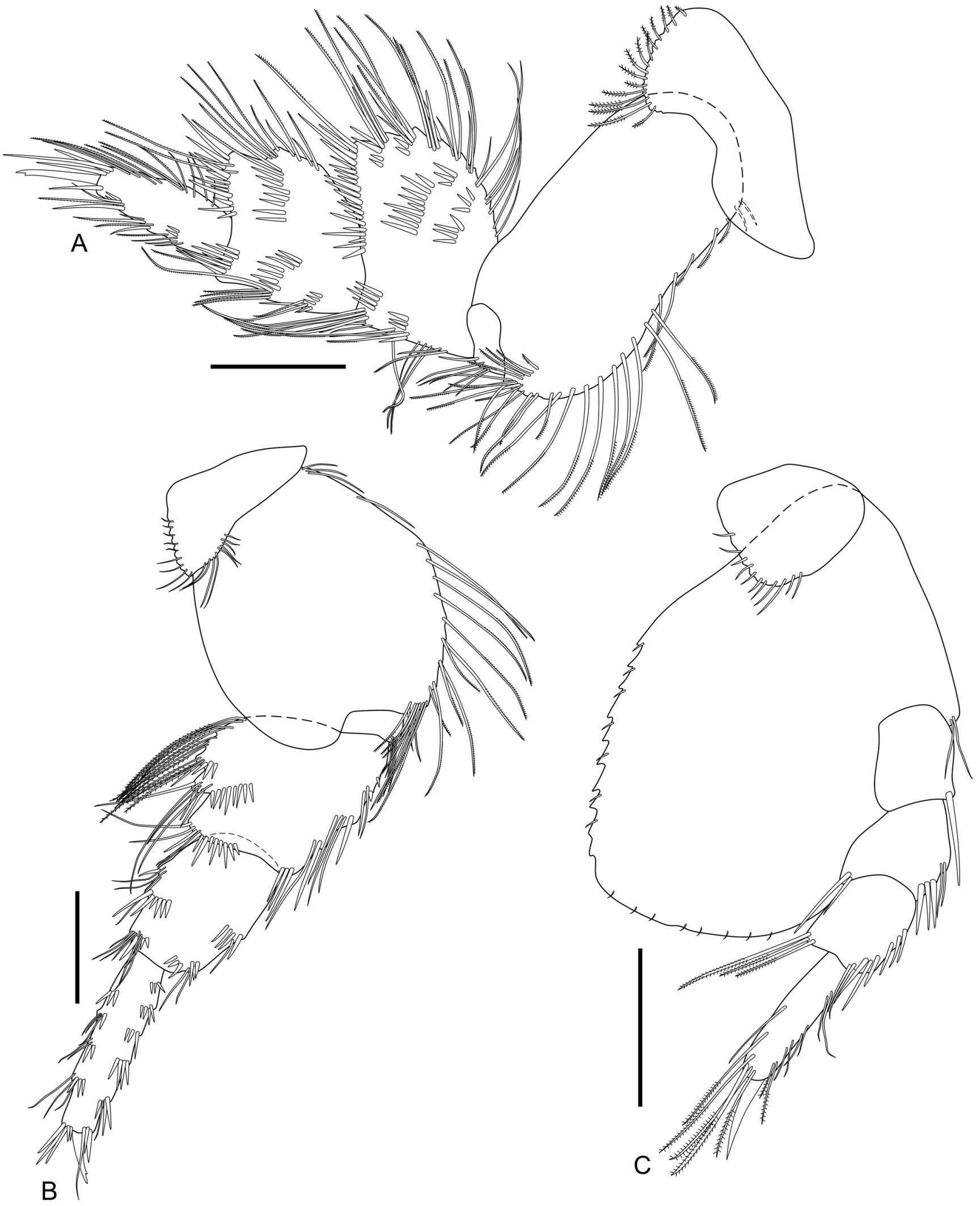

Figure 15. Metharpinia iado Alonso de Pina, 2003, female (UERJ 423): (A) Right pereopod 5; (B) Right pereopod 6; (C) Right pereopod 7. Scale bars: $0.5 \mathrm{~mm}$. 
setae, bearing 1 subapical nail; inner ramus, dorsal margin with 3 stout setae, bearing 1 subapical nail. Uropod 3 (Fig. 16F), peduncle, about $1.5 \times$ longer than wide, ventral margin with 5 stout setae, dorsal margin with 1 simple and 1 stout seta; outer ramus, $1.3 \times$ longer than inner, article 1 , dorsal margin with 5 plumose setae, ventral margin with
3 acclivities, stout setae formula: 3-3-3-3, article 2, elongate, with 2 plumose setae apically; inner ramus, margins with long stout setae. Telson (Fig. 16G), about 75\% cleft, apex obliquely truncate with inner corner produced into a tooth, with 1 plumose and 5 stout setae on each lobe, dorsolateral margin with 7 long setae on each side.
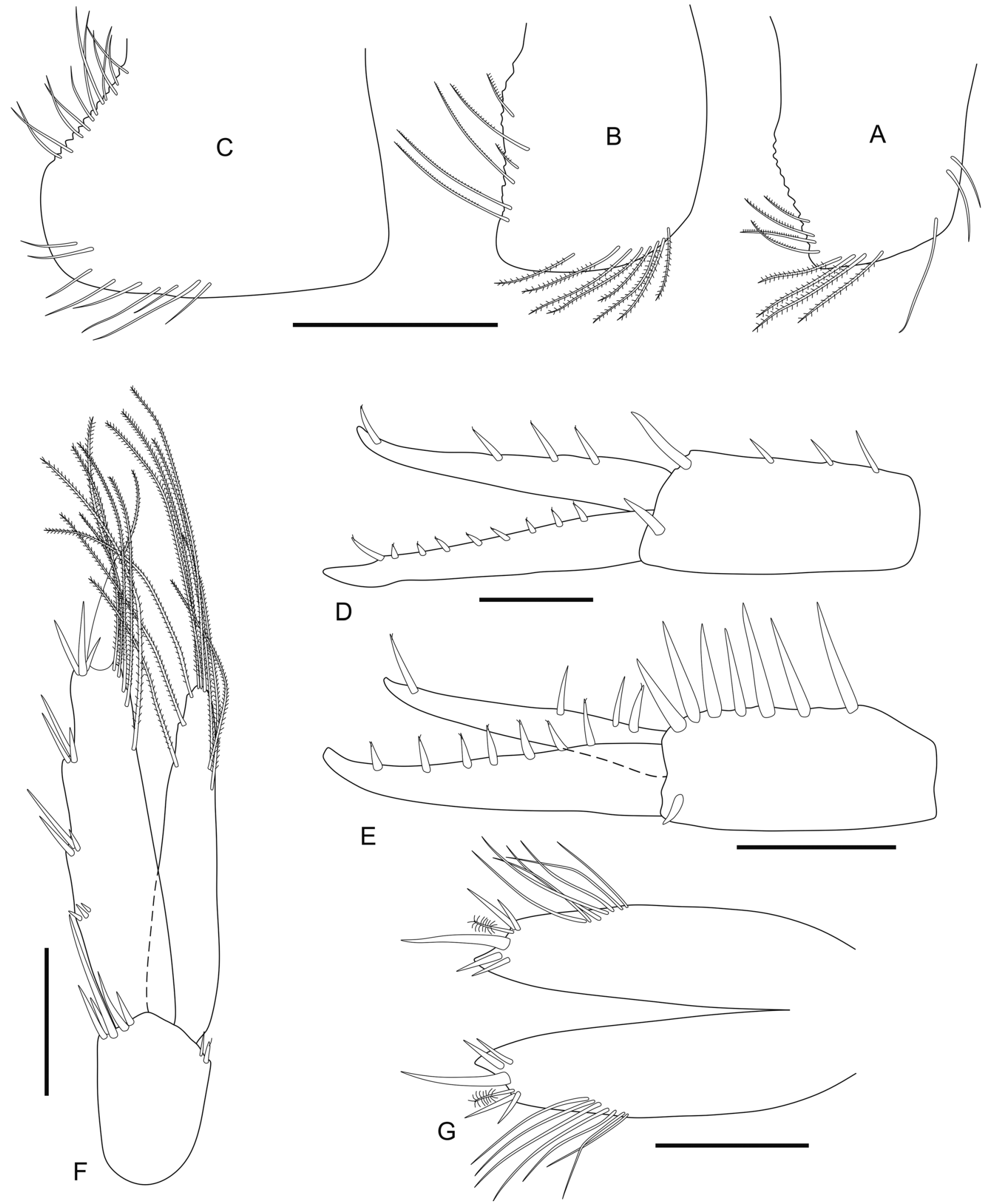

Figure 16. Metharpinia iado Alonso de Pina, 2003, female (UERJ 423): (A) Right epimeral plate 1; (B) Right epimeral plate 2; (C) Right epimeral plate 3; (D) Right uropod 1; (E) Right uropod 2; (F) Right uropod 3; (G) Telson. Scale bars: $0.5 \mathrm{~mm}$ for A-C; $0.2 \mathrm{~mm}$ for the remaining. 
Sexual dimorphism: Based on male (UERJ 424). Body (Fig. 12B), smaller in size. Head (Fig. 17A, B), eyes, larger and more pigmented; rostrum, constricted, narrow, elongate and spatulate. Antenna 1 (Fig. 17C), peduncle article 1 , about $1.4 \times$ longer than wide, ventral margin with 1 plumose seta, dorsal margin with 2 setae distally; article 2, ventral margin with short to long pectinate setae; article 3, short; primary flagellum 10-articulate, with calceoli on articles 1-3; accessory flagellum 9-articulate. Antenna 2 (Fig. 17D), peduncle article 3, dorsal margin covered with setules; article 4, ventral margin with short to long setae, dorsal margin with 1 stout and 4 long se-

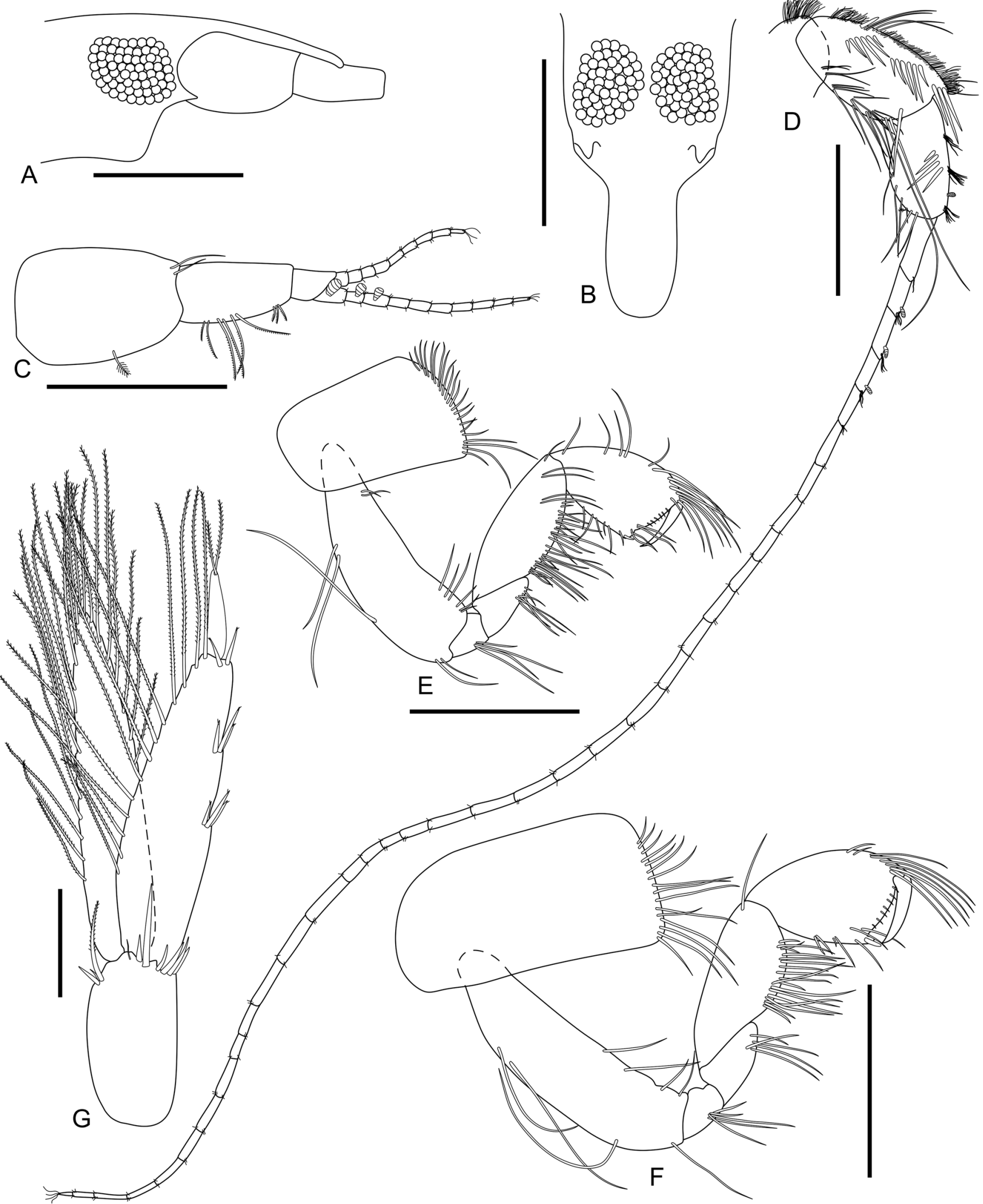

Figure 17. Metharpinia iado Alonso de Pina, 2003, male (UERJ 424): (A) Head in lateral view; (B) Head in dorsal view; (C) Right antenna 1; (D) Right antenna 2; (E) Right gnathopod 1; (F) Right gnathopod 2; (G) Right uropod 3. Scale bars: $0.5 \mathrm{~mm}$ for A-F; $0.2 \mathrm{~mm}$ for $\mathrm{G}$. 
tae, covered with setules, facial stout setae formula: 3-6-6; article 5, ventral margin with short to long setae, dorsal margin with 3 tufts of setae and 1 calceolus distally, facial margin with 4 stout setae; flagellum 36 -articulate, with calceoli on articles 2-4.

Gnathopods 1-2 (Fig. 17E, F), similar in size, but more robust than in female.

Uropod 3 (Fig. 17G), peduncle, 1.9× longer than wide, with 6 stout setae distally, dorsal margin with 3 setae; outer ramus, article 1, ventral margin with two acclivities, stout setae formula: 3-3-2, dorsal margin covered with long plumose setae, article 2, with 2 medium plumose setae apically; inner ramus, slightly shorter than outer, margins covered with long plumose setae.

Type locality: Argentine Sea, El Rincón, Buenos Aires, Argentina (394 $\left.49^{\prime} 49^{\prime \prime} \mathrm{S}, 61^{\circ} 50^{\prime} 30^{\prime \prime} \mathrm{W}\right)$.

Remarks: Metharpinia iado was described with material from Buenos Aires (Argentina) and this is the first record of the species for Brazilian waters. According to Alonso de Pina (2003a), this is species is similar to M. longirostris. However, it can be distinguished by $M$. longirostris by the following states of characters ( $M$. longirostris characters in parenthesis): antenna 2, peduncle article 4, stout setae formula: 1-3-6-5 (1-3-8-4); gnathopods 1-2, palm acute (almost transverse); pereopod 7, basis posteroventrally expanded, reaching apex of carpus (reaching apex of merus); epimeral plate 3, posterior margin strongly convex (weakly convex); telson, with 4 stout setae on each lobe (2-3 stout setae).

Geographic distribution: Argentina: Argentine Sea; Brazil: coast of the Santa Catarina state.

Bathymetric range: 9-27 m depth.

\section{Identification key to world species of Metharpinia}

1 Urosomite 3, with large acute hook dorsally......................................... 2

- Urosomite 3, without large acute hook dorsally...................................... 3

2 Uropod 2, inner ramus ordinary... M. dentiurosoma Alonso de Pina, 2003

- Uropod 2, inner ramus stout and short .

M. grandirama Alonso de Pina, 2003

3 Maxilla 1, palp ordinary ..................................................................... 4

- Maxilla 1, palp narrow..... M. taylorae Andrade, Johnsson \& Senna, 2015

4 Maxilliped, inner plate with 1 stout seta apically................................... 5

- Maxilliped, inner plate with 2 stout setae apically.................................. 7

5 Pereopod 7, basis reaching apex of carpus ............................................. 6

- Pereopod 7, basis reaching apex of merus ............................................

M. longirostris Schellenberg, 1931

6 Epimeral plate 2, posterior margin crenulate

M. iado Alonso de Pina, 2003

— Epimeral plate 2, posterior margin smooth

M. floridana (Shoemaker, 1933)

7 Epimeral plate 3, posteroventral corner without projection..................... 8

- Epimeral plate 3, posteroventral corner with an acute projection ........... 9
8 Uropods 1-2, rami without apical nails......... M. oripacifica Barnard, 1980 - Uropods 1-2, rami bearing apical nails............ M. coronadoi Barnard, 1980

9 Epimeral plate 3, facial margin with an oblique row of setae. M. protuberantis Alonso de Pina, 2001

— Epimeral plate 3, facial margin naked. M. jonesi (Barnard, 1963)

\section{Genus Microphoxus Barnard, 1960}

Type species: Microphoxus minimus Barnard, 1960

Diagnosis (emended from Barnard, 1980; Alonso de Pina, 2003b): Eyes present. Antennae 1-2, flagella unreduced in female. Antenna 1, article 2 ordinary, ventral setae widely spread. Antenna 2, article 1 not ensiform, article 4 in 1 or more rows; article 5 ordinary in size. Right mandibular incisor with 3 teeth, molar not triturative, small, pillow-shaped, bearing 3 or more splayed stout setae, not bearing fuzz, palpar hump small. Maxilla 1, palp 2-articulate, inner plate with 1-4 setae. Maxilliped, inner plate ordinary, apex of palp article 3 not protuberant, article 4 elongate, apical nail distinct, articulate, medium to elongate. Gnathopods 1-2 ordinary, small, similar, carpus free, elongate, palms almost to totally transverse, propodus ovatorectangular. Pereopods 3-4, propodus with thin facial setae. Pereopod 5, ischium broad. Pereopod 7, basis naked ventrally, ischium and dactylus ordinary. Epimeral plates 1-2 lacking or bearing numerous long posterior setae. Epimeral plate 3 ordinary. Urosomite 1 generally naked except for ventral bundle of for sparse apicoventral setae near base of uropod 1. Urosomite 3 with dorsal hook or special process. Uropods 1-2, no rami with stout setae continuously to apex. Inner ramus of uropod 2 ordinary. Uropod 3, outer ramus 2-articulate, article 2 elongate, with 2 apical setae.

Composition of the genus: The genus is composed by 5 species: Microphoxus breviramus Bustamante, 2002; Mi. cornutus (Schellenberg, 1931); Mi. minimus Barnard, 1960; Mi. moraesi Bustamante, 2002; Mi. uroserratus Bustamante, 2002.

\section{Microphoxus cornutus (Schellenberg, 1931) (Figs. 18-22)}

Metharpinia cornuta Schellenberg, 1931: 68, 269, 273, fig. 35. Dahl, 1952: 18. Barnard \& Drummond, 1976: 522, 528. Barnard \& Drummond, 1978: 24, 32, 145, 416. Barnard, 1979: 370.

Paraphoxus cornuta Barnard, 1958: 117.

Paraphoxus cornutus Barnard, 1960: 186, 194, 224, 271, 290. Lowry \& Bullock, 1976: 126.

Microphoxus cornutus Barnard, 1980: 106, 110. Wakabara et al., 1982: 68. Barnard \& Karaman, 1991: 623. González, 1991: 50, 61. Wakabara et al., 1991: 74. Valério-Berardo, 1992: 23. De Broyer \& Jazdzewski, 1993: 84. Jarrett \& Bousfield, 1994: 64. Wakabara \& Serejo, 1998: 578. Pires-Vanin et al., 1997: 36, 38. De Broyer \& Rauschert, 1999: 286. Valério-Berardo et al., 
2000: 65. Alonso de Pina, 2001: 535. Bustamante, 2002: 62, 70, 76, 77. Scelzo et al., 2002: 48, 51, 53. Alonso de Pina, 2003a: 1029, 1030, 1045, 1055, 1057, figs. 10-12, 16. Arasaki et al., 2004: 258. Chiesa et al., 2005: 171, fig. 2B. Muniz \& Pires-Vanin, 2005: 16. López-Gappa et al., 2006: 17, 52. Chiesa \& Alonso, 2007: 108. De Broyer et al., 2007: 190. Alonso de Pina et al., 2008: 19. González et al., 2008: 167. Ferrando et al., 2010: 348. Mendez et al., 2010: 431. Senna, 2010: 2077, 2116. Alonso, 2012: 1884. Pires-Vanin et al., 2013: 47. Pires-Vanin et al., 2014: 802. Andrade et al., 2015: 33. Soto et al., 2017: 437. Serejo \& Siqueira, 2018: 36.

Material examined: 3 우, in ethanol 70\%, MBT 152, $23^{\circ} 03^{\prime} \mathrm{S}, 41^{\circ} 10^{\prime} \mathrm{W}, 98 \mathrm{~m}$ depth, Rio de Janeiro state, 04 September 1970 (UERJ 429); 1 \%, dissected and drawn,

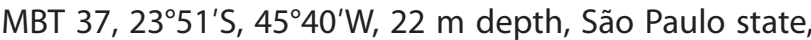
06 May 1970 (UERJ 426); $10^{\prime}$, dissected and drawn, MBT $37,23^{\circ} 51^{\prime} \mathrm{S}, 45^{\circ} 40^{\prime} \mathrm{W}, 22 \mathrm{~m}$ depth, São Paulo state, 06 May 1970 (UERJ 427); 3 우 and $20^{\circ} 0^{\circ}$, in 70\% ethanol, MBT 37, $23^{\circ} 51^{\prime} \mathrm{S}, 45^{\circ} 40^{\prime} \mathrm{W}, 22 \mathrm{~m}$ depth, São Paulo state, 06 May 1970 (UERJ 428); 4 \%o and $20^{\circ} \sigma^{\prime \prime}$, in 70\% ethanol, MBT 37, $23^{\circ} 51^{\prime} \mathrm{S}, 45^{\circ} 40^{\prime} \mathrm{W}, 22 \mathrm{~m}$ depth, São Paulo state, 06 May 1970 (MZUSP 41108).

Diagnosis: Head, eyes rounded and medium-sized; rostrum narrow and short, reaching apex of article 1 of antenna 1 . Antenna 1 , article 2 , with ventral setae widely spread. Antenna 2, article 4, with 3-4 rows of facial stout setae. Mandible, molar as a small hump with stout setae. Maxilliped, inner plate with 1 stout seta apically; palp, article 4 elongate with medium apical nail, partially embedded. Gnathopods 1-2, weakly setose, palm almost transverse, palpar hump small. Pereopods 5-6 stout and setose. Pereopod 7, basis expanded posteroventrally, almost reaching apex of carpus. Epimeral plate 2, ventral margin with long plumose setae. Epimeral plate 3, posteroventral corner rounded, posterior margin weakly serrate, with long setae. Urosomite 1, with a tuft of ventral setae. Urosomite 3, produced as a large acute hook dorsally. Uropods 1-2, rami not continuously setose to apex. Uropod 3, outer ramus, article 2 elongate, with 2 setae apically. Telson, deeply cleft, with 2 stout setae and variable simple setae on each lobe.

Description: Based on female (UERJ 426). Habitus as in Fig. 18A. Head (Fig. 19A, B), eyes rounded and medium-sized; rostrum narrow and short, reaching apex of article 1 of antenna 1. Antenna 1 (Fig. 19C), peduncle article 1 about $1.3 \times$ longer than wide, ventral margin with 4 brush setae distally, dorsal apex with 1 seta; article 2, ventral margin with 5 long setae medially, dorsal margin with 1 short seta distally; article 3, short, ventral margin with 2 setae; primary flagellum 6-articulate; accessory flagellum 5-articulate. Antenna 2 (Fig. 19D), peduncle article 3, short and rounded, dorsal margin with 1 seta; article 4, stout setae formula: 1-3-2-3, ventral margin with long setae and 1 brush seta proximally, dorsal margin with 1 stout and 1 long seta medially; article 5, ventral margin with 3 long setae, facial margin with 2 stout setae medially and 5 long setae distally; flagellum 7-articulate. Right mandible (Fig. 19J), molar as a small hump with 4 stout setae, incisor with 3 teeth, lacinia mobilis bifid, accessory setal row with 5 stout setae, palpar hump small; palp 3-articulate, article 1 short, article 2 ordinary, article 3 slightly longer than article 2, apex oblique, with 7 medium to long setae. Maxilliped (Fig. 19l), inner plate with 1 stout seta apically and 4 setae; outer plate with 6 stout setae; palp, article 1 with 1 apicolateral setae, article 2, medial margin moderately setose, article 3 , weakly setose, article 4, elongate, with medium apical nail, partially embedded.

Gnathopod 1 (Fig. 20A), coxa subrectangular, ventral margin with 10 setae; basis elongated, anterior margin with few short to long setae, posterior margin with 2 setae medially and 3 distally; ischium, small and subrectangular, posterior margin with 2 setae; merus, posterior margin with 5 setae; carpus, anterior margin with 1 seta distally; posterior margin moderately setose; propodus, anterior margin weakly setose, with a tuft of setae distally, posterior margin weakly setose; palm almost transverse, with setules, palmar hump small; dactylus reaching the palmar corner. Gnathopod 2 (Fig. 20B), coxa subrectangular, ventral margin with 9 setae; basis elongated, about $5 \times$ longer than wide, anterior margin with 2 setae, posterior margin with 2 setae medially and 3 distally; ischium, small and subrectangular, posterior margin with 2 setae; merus, posterior margin with 3 setae; carpus, anterior margin with 1 seta distally, posterior margin moderately setose; propodus, anterior margin setose distally, posterior margin weakly setose; palm almost transverse, with setules, palmar hump small, dactylus reaching the palmar corner. Pereopod 3 (Fig. 21A), coxa subrectangular, ventral margin with 6 setae; basis, posterior margin with 2 setae medially and distally; ischium, small and subrectangular, posterodistal corner with 2 setae; merus, anterior margin with 1 seta distally, posterior margin with long setae medially and distally, facial margin with a distal row of 6 setae; carpus, posterior margin with 7 long setae, facial margin with a medial row of 5 long setae; propodus, anterior margin with 1 short seta distally, posterior margin with 5 stout setae; dactylus, about $30 \%$ the length of propodus. Pereopod 4 (Fig. 21B), coxa subtriangular, ventral margin with 4 setae, posterodorsal margin weakly excavate; remaining articles are very similar to pereopod 3, differing only by some arrangements of setae. Pereopod 5 (Fig. 21C), coxa bilobate, posterior lobe with 6 setae; basis, anterior margin with some long and 2 stout setae, anterodistal corner with a row of 5 setae, posterior margin naked; ischium, small and subrectangular, anterodistal corner with a row of 6 setae; merus stout, slightly longer than wide, margins with medium to long setae, facial stout setae formula: 5-3-8-4-7-4-7; carpus stout, slightly longer than wide, margins with medium to long setae, facial stout setae formula: 4-1-4-5-5-5-3; propodus, margins weakly setose, facial margin with 5 stout setae; dactylus, about $55 \%$ the length of propodus. Pereopod 6 (Fig. 21D), coxa, weak- 
ly expanded posteroventrally, with 2 setae; basis, anterior margin moderately setose, anterodistal corner with a row of 5 setae, posterior margin naked; ischium, small and subrectangular, anterodistal corner with 2 long setae; merus stout, slightly longer than wide, anterior margin moderately setose, posterior margin weakly setose, facial stout setae formula: 4-6-2-4-9; carpus stout, about $1.2 \times$ longer than wide, margins weakly setose, facial stout setae formula: 4-5-4-3-3; propodus, margins weakly setose, facial margin with 6 stout setae; dactylus, about $25 \%$ the length of propodus. Pereopod 7 (Fig. 21E), coxa subtriangular, posteroventral margin with 2 setae; basis, about $1.3 \times$ longer than wide, posteroventrally expanded, reaching the half of carpus, anterior margin with 2 setae proximally and 1 distally, posterior margin serrate; ischium, small and subquadrate, anterodistal corner with
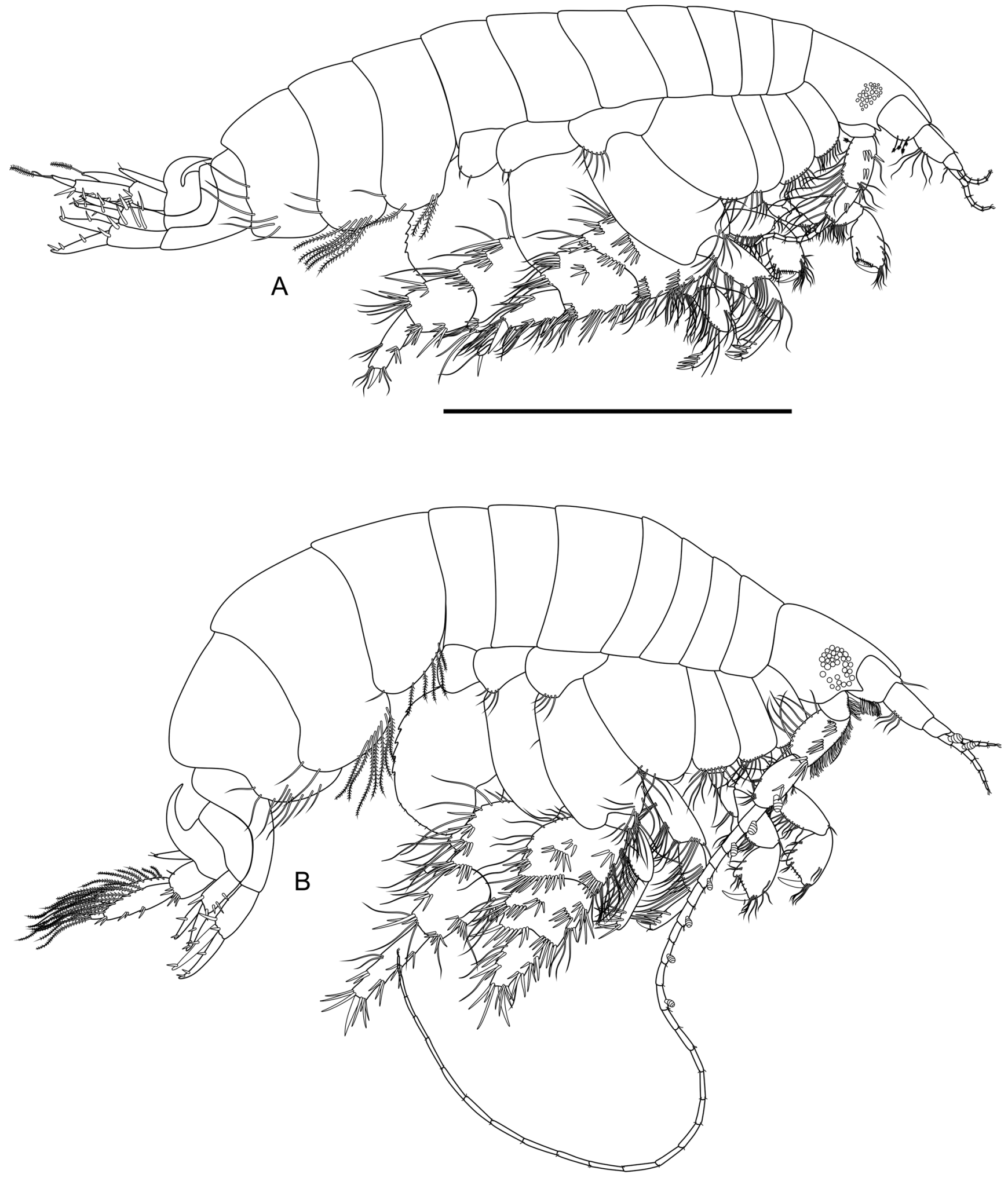

Figure 18. Microphoxus cornutus (Schellenberg, 1931): (A) Habitus of female (UERJ 426); (B) Habitus of male (UERJ 427). Scale bars: $1.0 \mathrm{~mm}$. 
1 long seta; merus, anterodistal corner with 1 long seta; carpus, anterior margin with 1 seta distally, posterodistal corner with 2 long setae; propodus, posterior margin with 1 long seta distally; dactylus, about $60 \%$ the length of propodus.
Epimeral plate 1 (Fig. 22A), anterior margin weakly concave, anteroventral corner with 2 long plumose setae, ventral margin with 1 long plumose seta, posterior margin rounded, with 1 seta. Epimeral plate 2 (Fig. 22B), anterior margin concave, ventral margin with 5 long

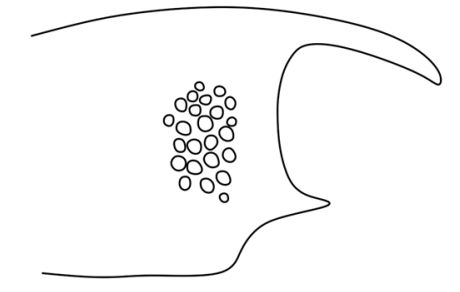

A
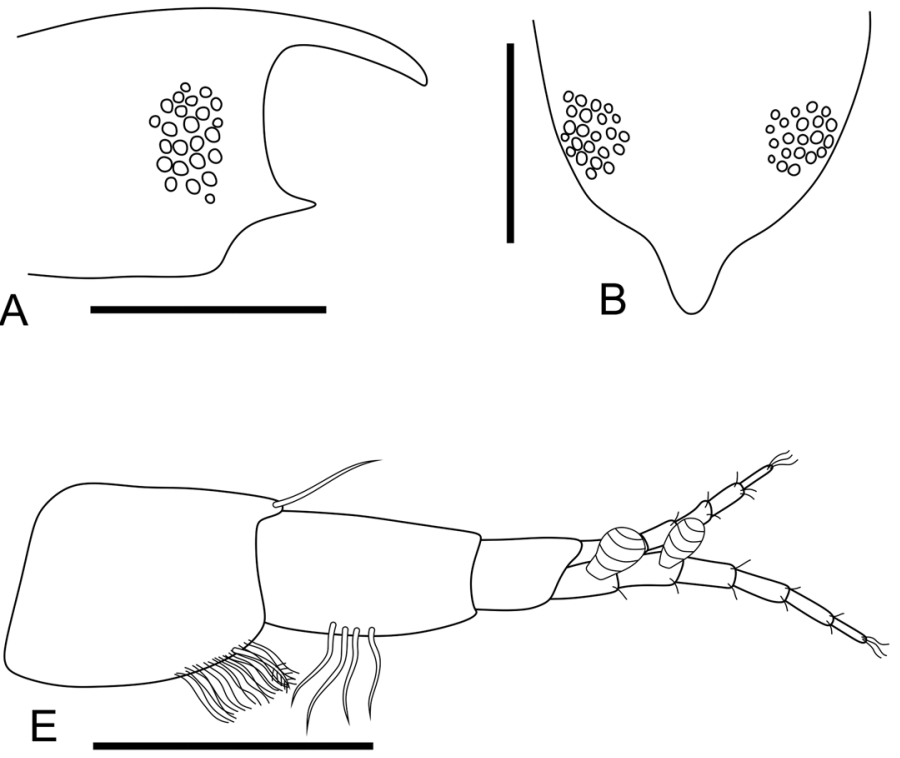
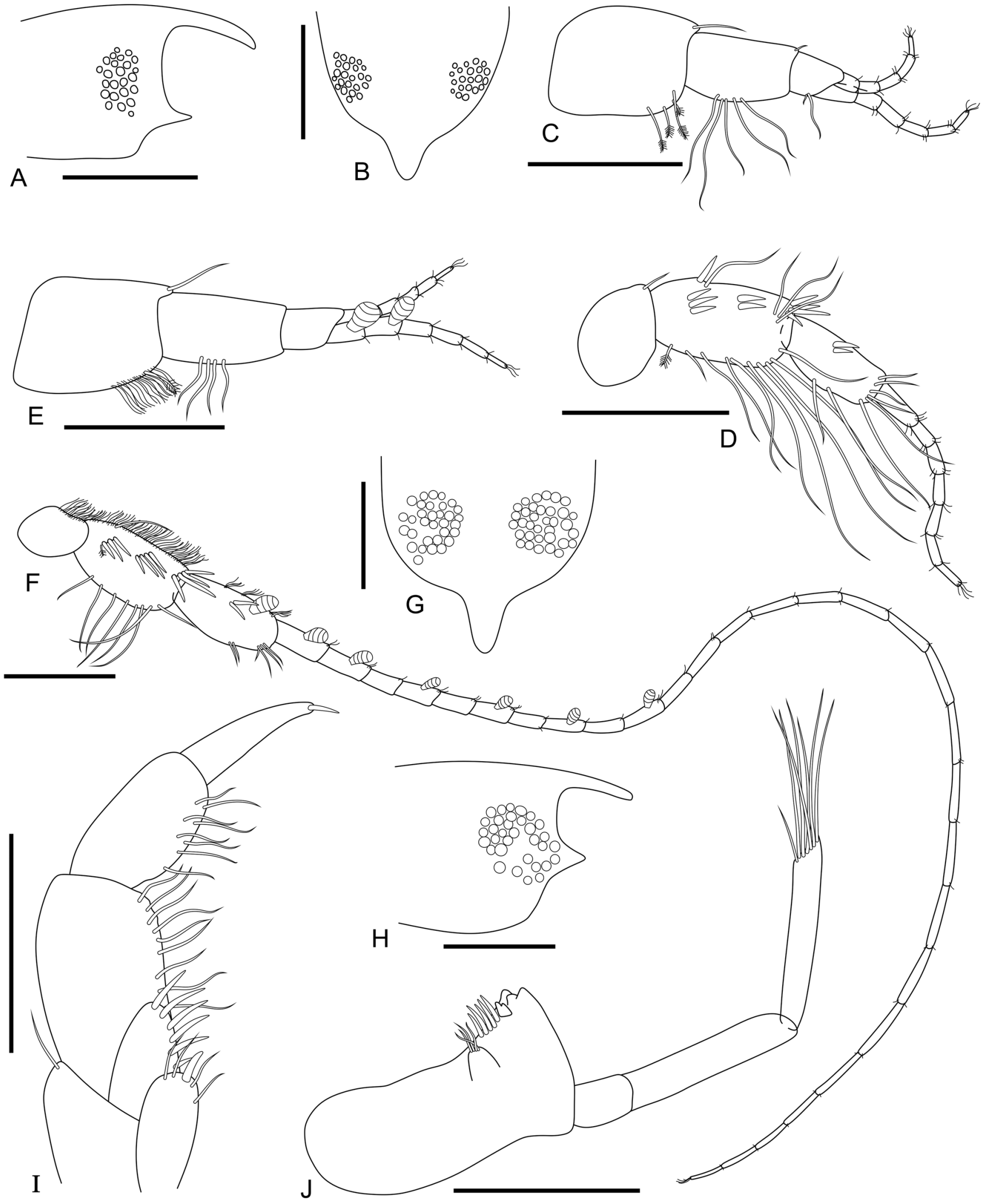

Figure 19. Microphoxus cornutus (Schellenberg, 1931): (A) Female head in lateral view; (B) Female head in dorsal view; (C) Female right antenna 1; (D) Female right antenna 2; (I) Left maxilliped; (J) Right mandible (UERJ 426); (E) Male right antenna 1; (F) Male right antenna 2; (G) Male head in dorsal view; (H) Male head in lateral view (UERJ 427). Scale bars: $0.1 \mathrm{~mm}$ for $\mathrm{I}-\mathrm{J} ; 0.2 \mathrm{~mm}$ for the remaining. 
plumose setae, posterior margin with 2 setae. Epimeral plate 3 (Fig. 22C), anterior margin concave, ventral margin with 3 setae extending to facial margin, posteroventral corner subquadrate, posterior margin nearly smooth, with 3 long setae. Urosomite 3, produced as a large acute

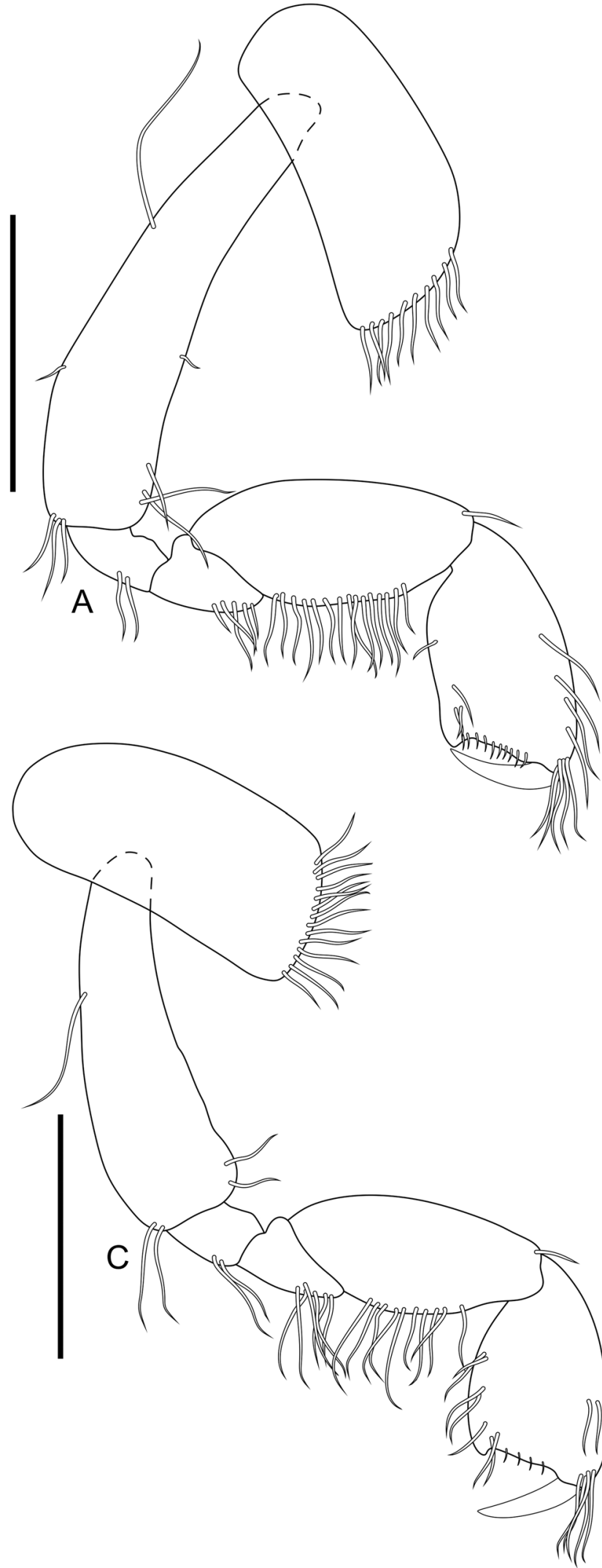

hook dorsally. Uropod 1 (Fig. 22D), peduncle, about 2.3x longer than wide, dorsomedial and lateral margins with 1 distal stout seta each; outer ramus, slightly longer than inner, dorsal margin with 2 stout setae, bearing 1 subapical nail; inner ramus, dorsal margin with 1 stout seta,
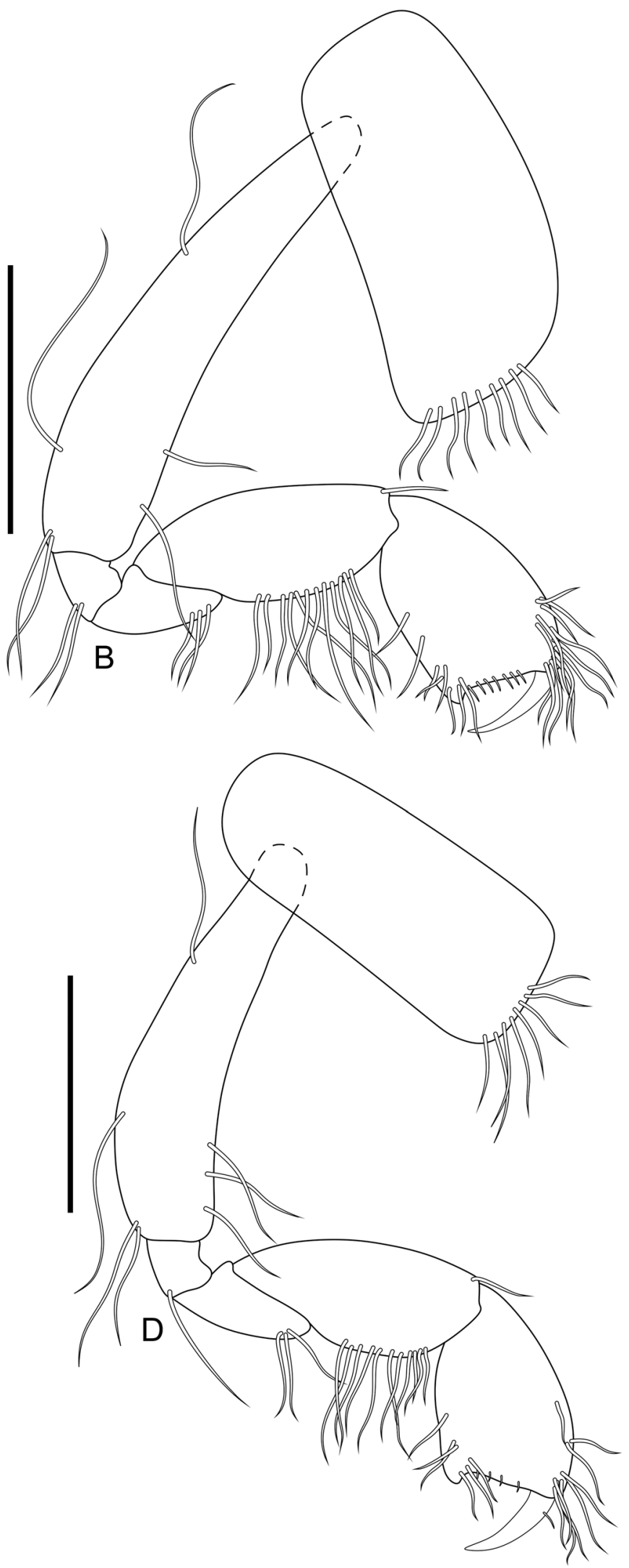

Figure 20. Microphoxus cornutus (Schellenberg, 1931): (A) Female right gnathopod 1; (B) Female right gnathopod 2 (UERJ 426); (C) Male right gnathopod 1; (D) Male right gnathopod 2 (UERJ 427). Scale bars: $0.2 \mathrm{~mm}$. 
bearing 1 subapical nail. Uropod 2 (Fig. 22E), peduncle, about $2.5 \times$ longer than wide, dorsomedial margin with 2 stout setae, ventrolateral margin with 3 long stout setae; outer ramus slightly longer than inner, dorsal margin with 2 stout setae, bearing 1 apical nail; inner ramus, dorsal margin with 1 stout seta, bearing 1 apical nail. Uropod 3 (Fig. 22F), peduncle, about 1.6x longer than wide, ventroapical margin with 4 stout setae, dorsoapical corner with 1 short stout seta; outer ramus, 1.5× longer than inner, article 1, ventral margin with 2 acclivities and
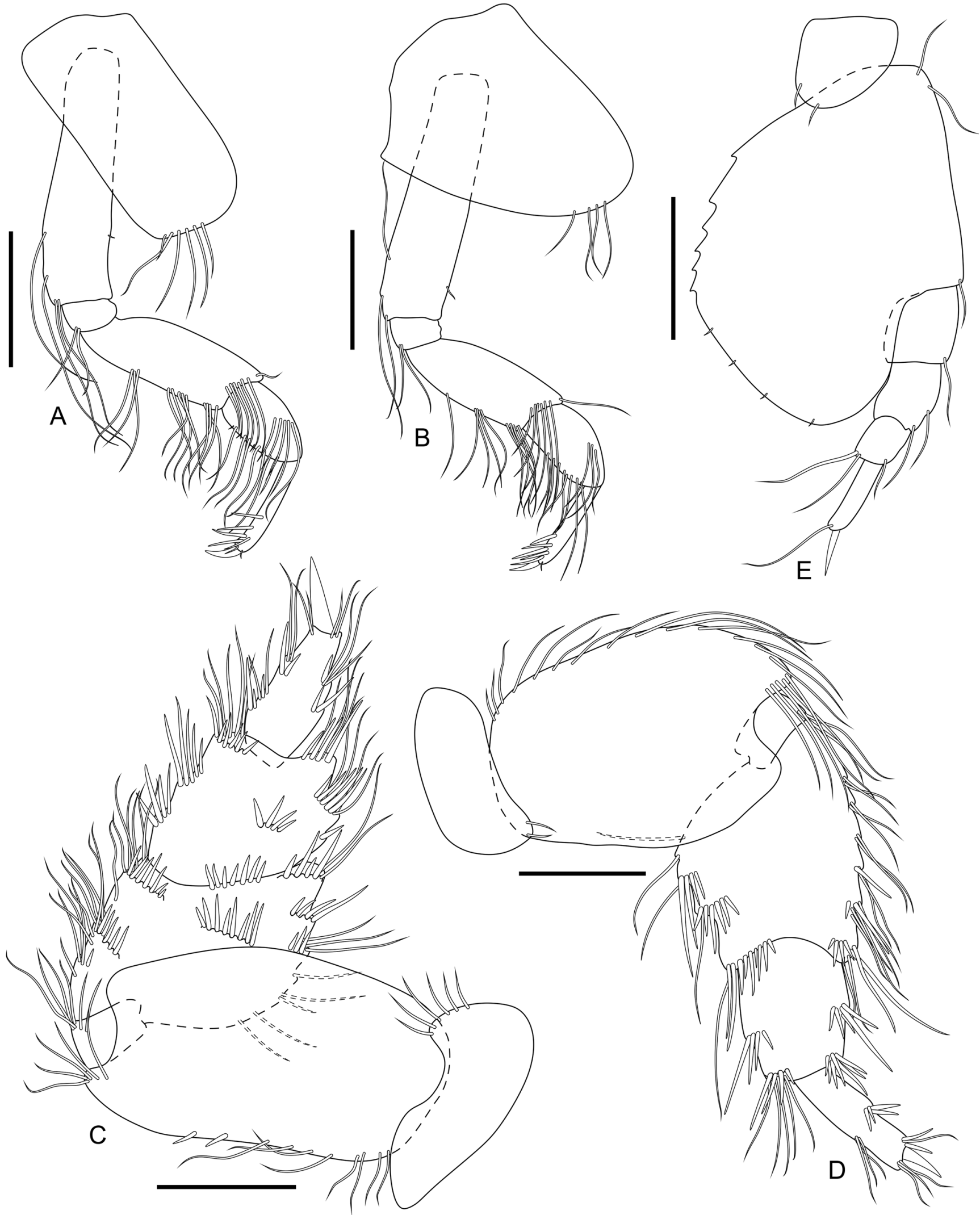

$\mathrm{E}$

Figure 21. Microphoxus cornutus (Schellenberg, 1931), female (UERJ 426): (A) Right pereopod 3; (B) Right pereopod 4; (C) Right pereopod 5; (D) Right pereopod 6; (E) Right pereopod 7. Scale bars: $0.2 \mathrm{~mm}$. 
2 stout setae on each, ventroapical corner with 2 stout setae, article 2, elongate, with 2 plumose setae apically; inner ramus, with 1 long plumose seta apically. Telson (Fig. 22G), about $85 \%$ cleft, apex rounded, apical margin with 1 brush and 2 stout setae on each lobe.

Sexual dimorphism: Based on male (UERJ 427). Body (Fig. 18B), smaller in size. Head (Fig. 19G, H) eyes, larger and more pigmented, rostrum narrow and short.
Antenna 1 (Fig. 19E), peduncle article 1, about 1.3× longer than wide, ventral margin with a row of setules and 1 brush seta distally, dorsal apex with 1 seta; article 2, ventral margin with 4 setae; article 3 short; primary flagellum 6-articulate, with calceoli on articles 1-2; accessory flagellum 6-articulate. Antenna 2 (Fig. 19F), peduncle article 3, short, dorsal margin covered with setules; article 4, facial stout setae formula: 1-3-4-3, ventral margin with medium to long setae, dorsal margin covered with
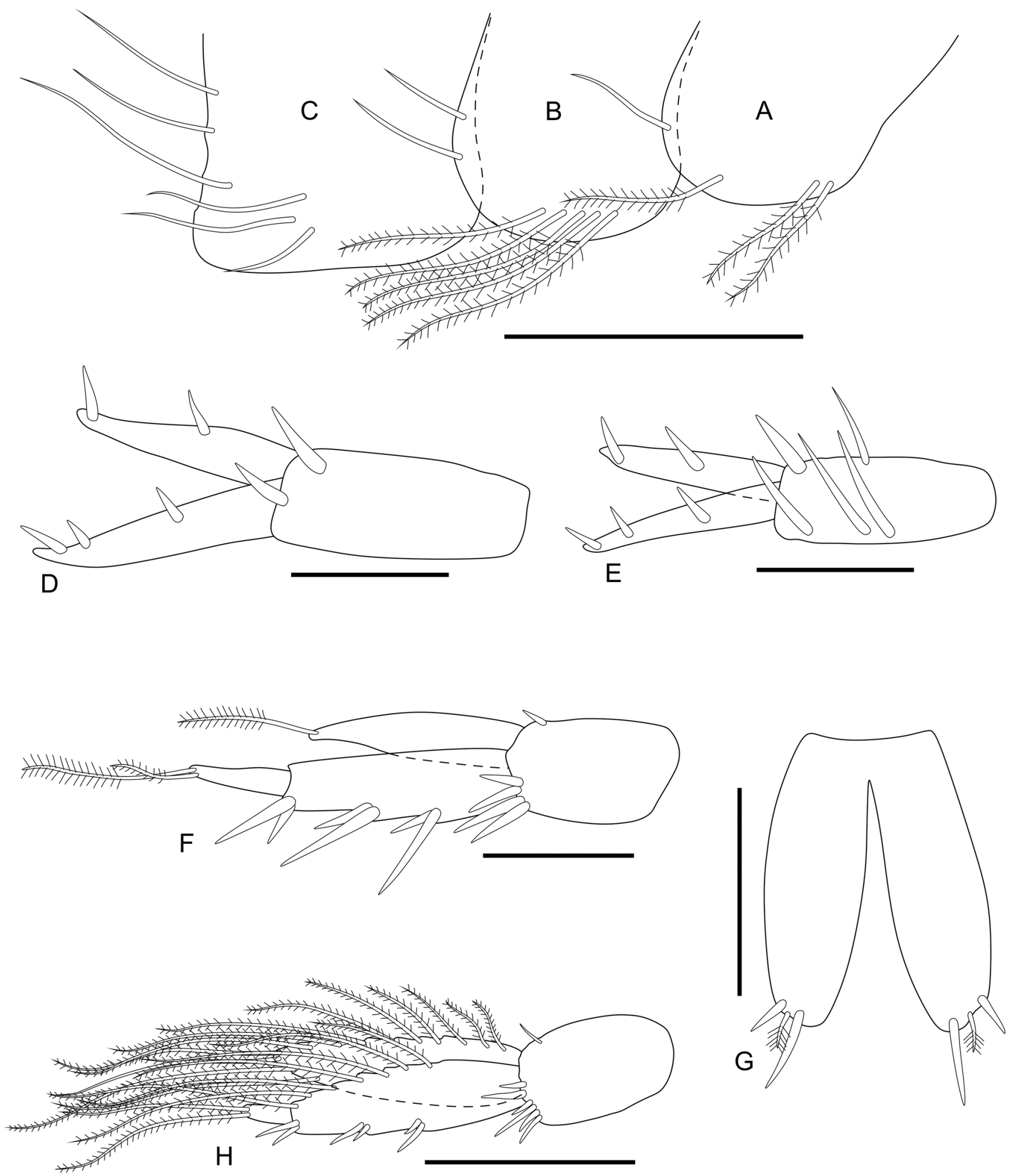

Figure 22. Microphoxus cornutus (Schellenberg, 1931): (A) Right epimeral plate 1; (B) Right epimeral plate 2; (C) Right epimeral plate 3; (D) Right uropod 1; (E) Right uropod 2; (F) Female right uropod 3; (G) Telson (UERJ 426); (H) Male right uropod 3 (UERJ 427). Scale bars: $0.2 \mathrm{~mm}$ for A-C; $0.1 \mathrm{~mm}$ for the remaining. 
setules, com 1 long seta medially; article 5, facial margin with 2 stout setae, ventral margin weakly setose, dorsal margin with 3 tufts of setules and 1 calceolous; flagellum 29-articulate and 6 calceoli.

Gnathopods 1-2 (Fig. 20C, D), subequal in size; basis shorter than in female.

Uropod 3 (Fig. $22 \mathrm{H}$ ), peduncle, about $1.6 \times$ longer than wide, ventroapical margin with 6 stout setae, dorsoapical corner with 1 seta; outer ramus, slightly longer than inner, article 1, ventral margin with 2 acclivities and 2 stout setae on each, ventroapical corner with 2 stout setae, article 2, elongate, with 2 plumose setae apically; inner ramus, margins covered with long plumose setae.

Type locality: Punta Arenas, Chile (5310'S, $\left.70^{\circ} 54^{\prime} \mathrm{W}\right)$.

Remarks: Microphoxus cornutus is distributed along south and southeastern coast of South America. The species is already known from Brazilian waters, being recorded for the state of São Paulo (Wakabara et al., 1991; PiresVanin et al., 1997; Valério-Berardo et al., 2000; Arasaki et al., 2004; Muniz \& Pires-Vanin, 2005; Pires-Vanin et al., 2014). This is the first record of the species for the Rio de Janeiro state coast. As reported by Alonso de Pina (2003a), it was possible to notice morphological variations among the collected individuals of Mi. cornutus in relation to characters such as: facial stout setae formula on articles 4-5 of antenna 2; number of stout setae on peduncle and rami of uropods 1-3; setation of epimeral plates 1-3; number of lateral setae on telson. These variations may reflect the maturation stage of the individuals, being the juveniles with fewer groups and weak armaments of setae, and the adults with stronger armaments of stout setae.

Geographic distribution: Argentina: Ushuaia Bay; Mar del Plata; Golfo Nuevo; Golfo San José; El Rincón; Chubut; Río Negro; Isla Monte León; Magellanic strait; and Beagle Channel. Brazil: municipalities of São Sebastião and Ubatuba, coast of São Paulo state; and Rio de Janeiro state. Chile: Valparaíso Bay; Puerto Montt; and Punta Arenas. Uruguay: north area (lat. aprox. $35^{\circ} 55^{\prime} \mathrm{S}$ ).

Bathymetric range: Shallow waters to $98 \mathrm{~m}$ depth.

\section{Microphoxus uroserratus Bustamante, 2002} (Figs. 23-27)

Microphoxus uroserratus Bustamante, 2002: 62, 69, 76, 77, figs. 7-12. Senna, 2010: 2077, 2116. Zalmon et al., 2013: 173, 176. Andrade et al., 2015: 33. Barros et al., 2017: 3. Negrello-Filho et al., 2018: 259, 260, 262, 263. Serejo \& Siqueira, 2018: 37.

Material examined: $1 \%$, dissected and drawn, MBT 163, $21^{\circ} 29^{\prime} \mathrm{S}, 40^{\circ} 56^{\prime} \mathrm{W}, 17 \mathrm{~m}$ depth, Rio de Janeiro state, 06 September 1970 (UERJ 431); 1 \%, dissected and drawn,
MBT 157, 21 ${ }^{\circ} 46^{\prime} \mathrm{S}, 40^{\circ} 58^{\prime} \mathrm{W}, 15 \mathrm{~m}$ depth, Rio de Janeiro state, 05 September 1970 (UERJ 430); $1 \%$, in 70\% ethanol, MBT 157, 21 ${ }^{\circ} 46^{\prime} \mathrm{S}, 40^{\circ} 58^{\prime} \mathrm{W}, 15 \mathrm{~m}$ depth, Rio de Janeiro state, 05 September 1970 (UERJ 432); $1 \%$, in 70\% ethanol, MBT 157, 21 ${ }^{\circ} 46^{\prime} \mathrm{S}, 40^{\circ} 58^{\prime} \mathrm{W}, 15 \mathrm{~m}$ depth, Rio de Janeiro state, 05 September 1970 (MZUSP 41109).

Diagnosis: Head, eyes rounded and medium-sized; rostrum reaching half of article 2 of antenna 1. Antenna 2, article 4, ventral margin with 4 groups of setae. Mandibles, lacinia mobilis with 2 teeth. Gnathopod 1, coxa with setae posteroventrally. Epimeral plate 3, facial margin with a row of 7 simple setae. Urosomite 3 , produced as a large acute hook dorsally. Uropod 1, peduncle without displaced stout seta; inner ramus with a row of stout setae dorsally. Uropod 2, peduncle with marginal stout setae; inner ramus without stout setae dorsally. Uropod 3, article 2 of outer ramus with 2 simple setae apically. Telson with 5 long setae dorsolaterally.

Description: Based on females (UERJ 430/UERJ 431). Habitus as in Fig. 23. Head (Fig. 24A, B), eyes rounded and medium-sized; rostrum constricted, narrow, elongate and spatulate, reaching half of article 2 of antenna 1. Antenna 1 (Fig. 24C), peduncle article 1 about 1.6× longer than wide, ventral margin with 3 brush setae, dorsal apex with 1 seta; article 2, ventral margin with 4 long setae, dorsal margin with 1 seta distally, facial margin with 1 brush and 1 long seta distally; article 3, short, ventral margin with 1 seta; primary flagellum 6-articulate; accessory flagellum 4-articulate. Antenna 2 (Fig. 24D), peduncle article 4, stout setae formula: 1-3-4-4, ventral margin with 4 groups of medium to long setae and 1 stout seta ventrodistally, dorsal margin with 1 long and 2 stout setae; article 5, ventral margin with 1 brush seta and few long setae, facial margin with 3 stout setae medially; flagellum 7-articulate. Left mandible (Fig. 24E), molar as a small hump with 6 stout setae, incisor with 3 teeth, lacinia mobilis with tiny cusps and 2 teeth, accessory setal row with 12 stout setae, palpar hump small; palp 3-articulate, article 1 short, article 2 with 3 short and 2 long setae, article 3 about $1.3 \times$ longer than article 2, apex oblique, with 10 medium to long setae. Right mandible (Fig. 24F), molar as a small hump with 6 stout setae, incisor with 3 teeth, lacinia mobilis bifid, accessory setal row with 11 stout setae, palpar hump small; palp 3-articulate, article 1 short, article 2 with 3 short and 2 long setae, article 3 about $1.4 \times$ longer than article 2, apex oblique, with 10 medium to long setae. Maxilla 1 (Fig. 24H), inner plate with 4 plumose setae apically; outer plate with 4 bifid stout setae and 6 multicuspidate stout setae apically; palp 2-articulate, article 2 with 2 stout setae apically, medial margin with 4 setae, facial margin covered with setules. Maxilla 2 (Fig. 24l), inner plate, medial margin covered with long setules, apical and apicomedial margins with plumose setae; outer plate, slightly longer than inner, lateral margin with setules, apicolateral margin 4 short setae, apical and apicomedial margins with 8 long setae. Maxilliped (Fig. 24G), inner plate with 2 stout setae apically and plumose setae on medial and apical 
margins; outer plate with 7 bipectinate stout setae; palp, article 1 with 3 apicolateral setae; article 2, lateral margin with 7 setae, medial margin setose, article 3, moderately setose, article 4, narrow, with medium apical nail, partially embedded.

Gnathopod 1 (Fig. 25A), coxa subrectangular, ventral margin with 11 setae; basis, anterior margin with 1 short and 1 long seta distally; ischium, small and subrectangular, posterior margin with 1 long seta; merus, posterior margin with 5 long setae; carpus, anterior margin with 1 seta distally, posterior margin weakly setose; propodus, anterior margin with a tuft of setae distally, posterior margin weakly setose, with 1 stout seta defining palm; palm almost transverse, with setules, palmar hump small; dactylus slightly longer than palm. Gnathopod 2 (Fig. 25B), coxa subrectangular, weakly expanded distally, ventral margin with 7 setae; basis, anterior margin with 5 setae, posterior margin with 2 long setae medially, posterodistal corner with 1 long seta; ischium, small and subrectangular, posterior margin with 1 long seta; merus, posterior margin with 6 long setae; carpus, anterior margin with 1 long seta distally, posterior margin weakly setose, facial margin with 1 seta distally; propodus, anterior margin with a tuft of setae distally, posterior margin weakly setose, with 1 stout seta defining palm; palm almost transverse, with setules, palmar hump large; dactylus reaching the palmar corner. Pereopod 3 (Fig. 25C), coxa subrectangular, ventral margin with 5 setae; basis, about $3 \times$ longer than wide, posterior margin with 3 setae; ischium, small and subrectangular, posterodistal corner with 1 seta; merus, anterior margin with 1 seta distally, posterior margin moderately setose, facial margin with a distal row of 4 long setae; carpus, posterior margin with 6 long setae, with 1 subdistal thicker stout seta extending $85 \%$ of propodus, facial margin with a row of 4 setae; propodus, anterior margin with 1 short seta distally, posterior margin with 3 stout setae, facial margin with 4 stout setae; dactylus, about 50\% the length of propodus. Pereopod 4 (Fig. 25D), coxa, subtriangular, posteroventral margin with 2 setae, posterodorsal margin weakly excavate; remaining articles are very similar to pereopod 3, differing only by some arrangements of setae. Pereopod 5 (Fig. 26A), coxa bilobate, posterior lobe with 5 setae ventrally; basis, anterior margin with 4 setae, anterodistal corner with a row of 4 setae extending to facial margin; ischium, small and subrectangular, anterodistal corner with a row of 4 setae extending to facial margin; merus more slender than in Mi cornutus, margins weakly setose, facial margin with 3 rows of stout setae: 5-4-6; carpus more slender than in Mi cornutus, margins weakly setose, facial margin with 4 rows of stout setae: 5-3-5-6; propodus, anterior margin with 1 long and 3 stout setae medially, distally with 1 long and 2 stout setae, posterior margin with 1 long and 2 stout setae distally; dactylus, about $70 \%$ the length of propodus, with a short acute tooth distally. Pereopod 6 (Fig. 26B), coxa weakly produced posteroventrally, posterior lobe with 4 pappose setae; basis, anterior margin with 4 setae; ischium, small and subrectangular, anterodistal corner with 1 seta; merus more slender than in Mi cornutus, anterior margin with 1 long and 1 stout seta proximally, 3 stout setae medially and 4 stout setae distally, posterior margin with 1 pappose seta proximally, 3 long and 2 stout medially and a row of 5 stout setae distally; carpus more slender than in Mi cornutus, anterior margin with 4 stout setae medially and 5 distally, posterior margin with 2 stout setae medially and 3 distally; propodus, anterior margin with 4 stout setae medially and 3 distally, posterior margin with 2 stout setae medially and 3 distally; dactylus, about $50 \%$ the length of propodus. Pereopod 7 (Fig. 26C), coxa subtriangular, posteroventral margin with 1 short seta; basis, slightly longer than wide, expanded posteroventrally, almost reaching apex of merus, anterodistal corner with 1 seta, posterior margin serrate; ischium, small and subquad-

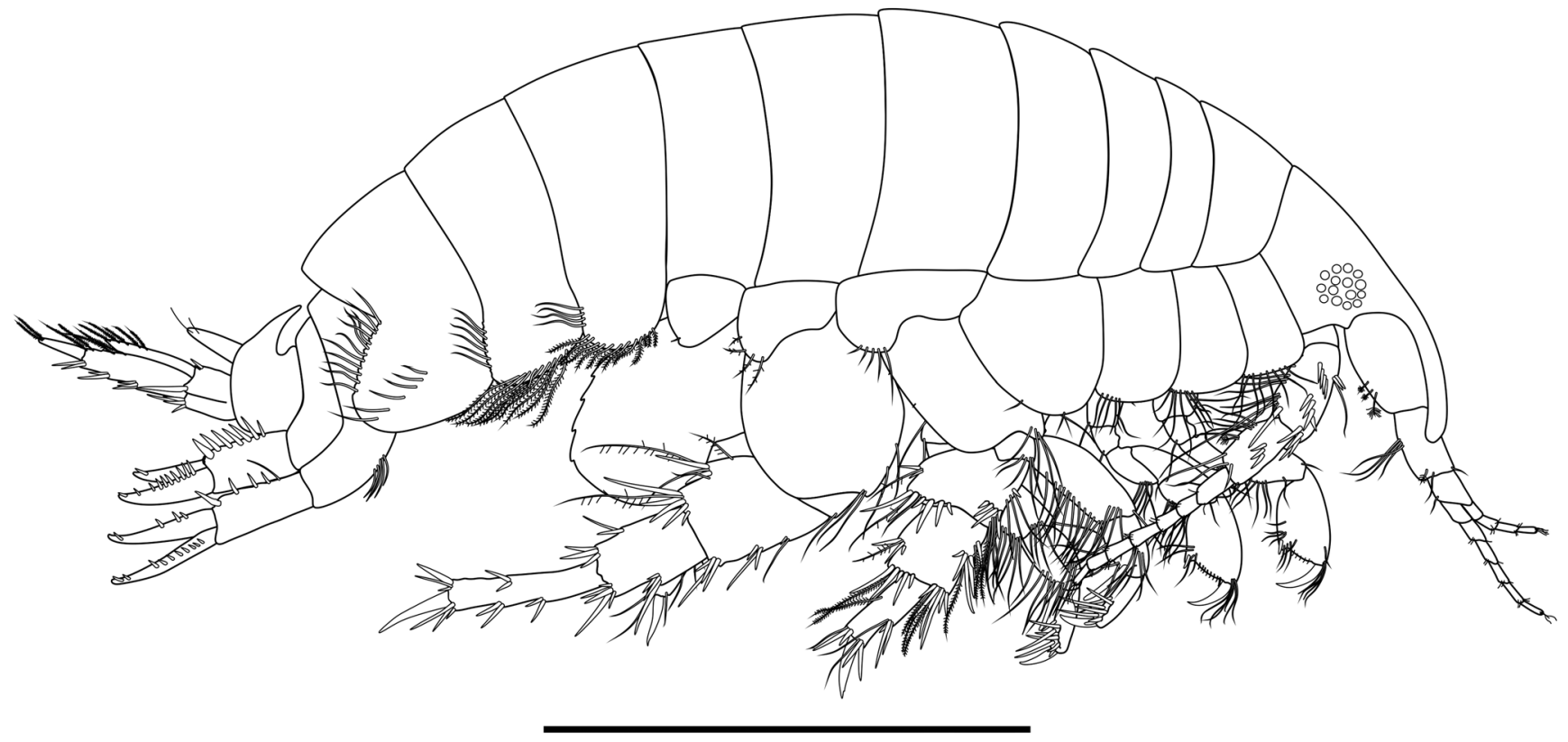

Figure 23. Microphoxus uroserratus Bustamante, 2002, female (UERJ 430): (A) Habitus. Scale bar: $1.0 \mathrm{~mm}$. 
rate, anterodistal corner with 1 seta; merus, anterior margin with 2 setae, posterior margin with 1 seta distally; carpus, anterior margin with 2 setae distally, posterior margin with 1 seta; propodus, anterior margin with 2 setae, posterior margin with 2 long setae distally; dactylus, about $75 \%$ the length of propodus.
Epimeral plate 1 (Fig. 27A), anteroventral margin rounded, ventral margin covered with plumose setae, posterior margin weakly concave, with 4 setae. Epimeral plate 2 (Fig. 27B), anteroventral margin rounded, ventral margin with 9 long plumose setae, posterior margin weakly crenulate, with 6 setae. Epimeral plate 3

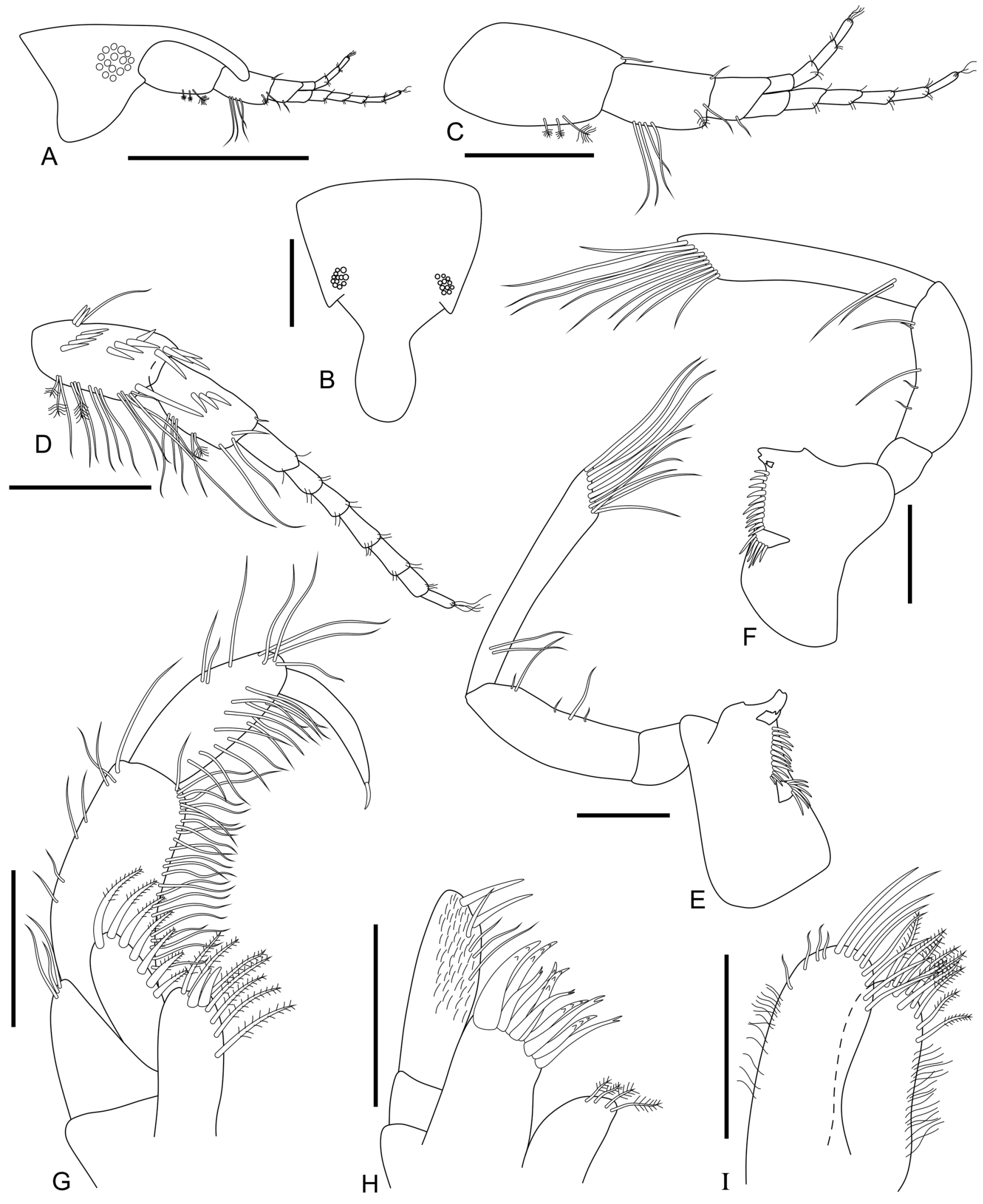

Figure 24. Microphoxus uroserratus Bustamante, 2002: (A) Head in lateral view; (C) Right antenna 1; (D) Right antenna 2 (UERJ 430); (B) Head in dorsal view; (E) Left mandible; (F) Right mandible; (G) Left maxilliped; (H) Left maxilla 1; (I) Left maxilla 2 (UERJ 431). Scale bars: $0.5 \mathrm{~mm}$ for A-B; $0.2 \mathrm{~mm}$ for the remaining. 
(Fig. 27C), anteroventral margin rounded, posteroventral corner with a row of 7 setae extending to facial margin, posterior margin weakly crenulate, with 12 setae. Urosomite 1, ventral margin with a tuft of setae. Urosomite 3, produced as a large acute hook dorsally.

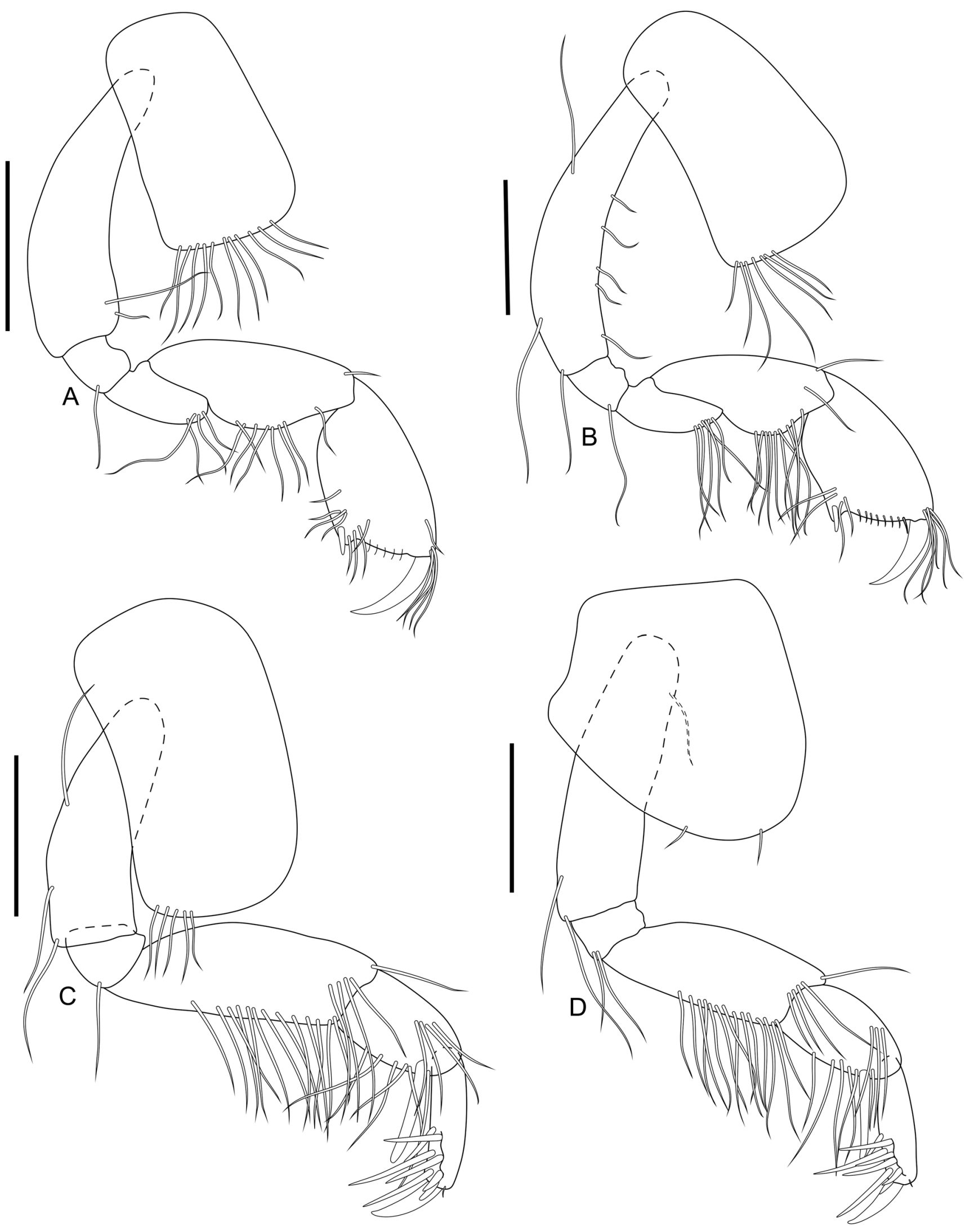

Uropod 1 (Fig. 27D), peduncle, about 2.4x longer than wide, dorsomedial margin with 1 long and 4 stout setae, apicolateral margin microscopically combed; outer ramus, slightly longer than inner, dorsal margin with 8 stout setae, bearing 2 subapical nails; inner ramus, dor-

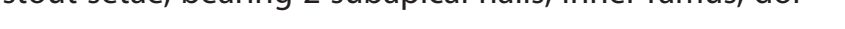

Figure 25. Microphoxus uroserratus Bustamante, 2002, female (UERJ 430): (A) Right gnathopod 1; (B) Right gnathopod 2; (C) Right pereopod 3; (D) Right pereopod 4 . Scale bars: $0.2 \mathrm{~mm}$. 
sal margin with 3 stout setae, bearing 1 subapical nail. Uropod 2 (Fig. 27E), peduncle, about $1.7 \times$ longer than wide, dorsomedialal margin with 6 stout setae, apicolateral margin microscopically combed, with 1 stout seta; outer ramus, slightly longer than inner, dorsal margin with 9 stout setae, bearing 1 subapical nail; inner ra-

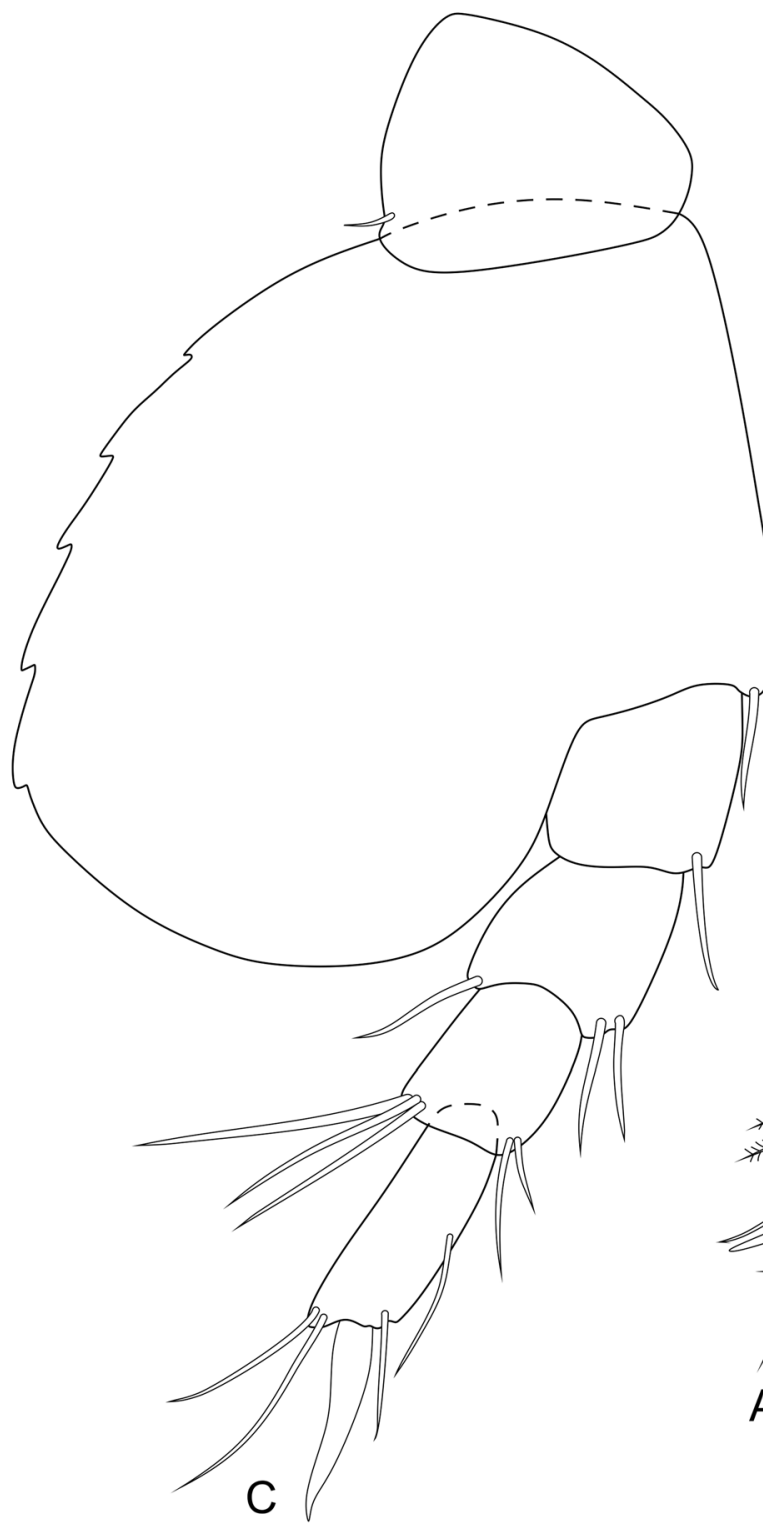

mus, dorsal margin bearing 1 subapical nail. Uropod 3 (Fig. 27F), peduncle, about $1.5 \times$ longer than wide, ventroapical margin with 4 stout setae, dorsoapical margin with 1 stout and 1 short seta, apicolateral margin with 1 long stout seta; outer ramus, $1.6 \times$ longer than inner, article 1, ventral margin with 2 acclivities bearing 3 and 2

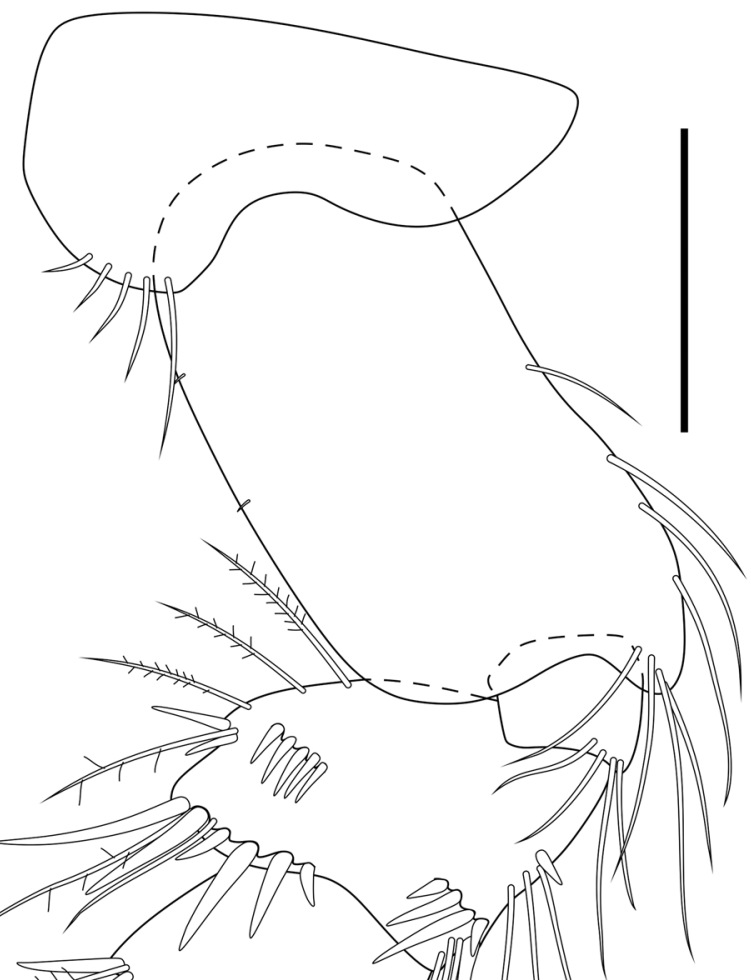

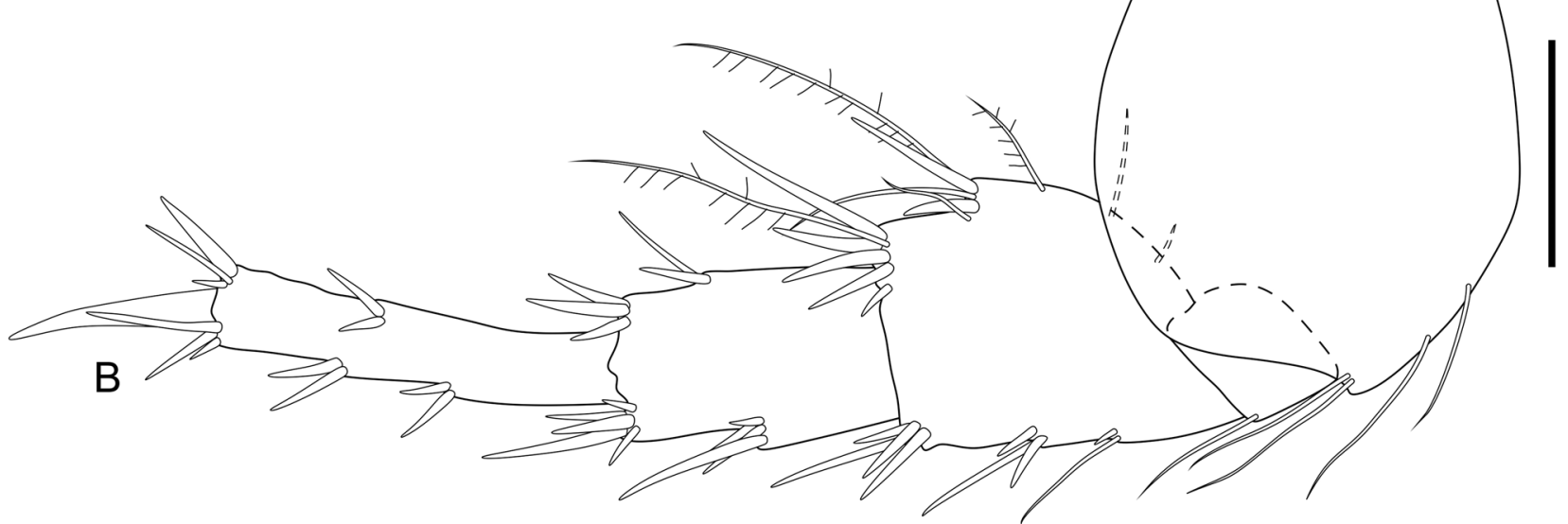

Figure 26. Microphoxus uroserratus Bustamante, 2002, female (UERJ 430): (A) Right pereopod 5; (B) Right pereopod 6; (C) Right pereopod 7. Scale bars: $0.2 \mathrm{~mm}$. 
stout setae respectively, distally with 2 stout setae, dorsal margin with 4 plumose setae, article 2, elongate, with 2 simple setae apically; inner ramus, dorsal margin with 5 long plumose setae. Telson (Fig. 27G), about $80 \%$ cleft, apical margin with 2 stout and 1 brush seta on each lobe, lateral margins with 5 long setae, dorsolateral margin with 2 brush setae on each side.

Type locality: Sepetiba Bay, Rio de Janeiro state $\left(22^{\circ} 58^{\prime} S\right.$, $\left.44^{\circ} 02^{\prime} \mathrm{W}\right)$.

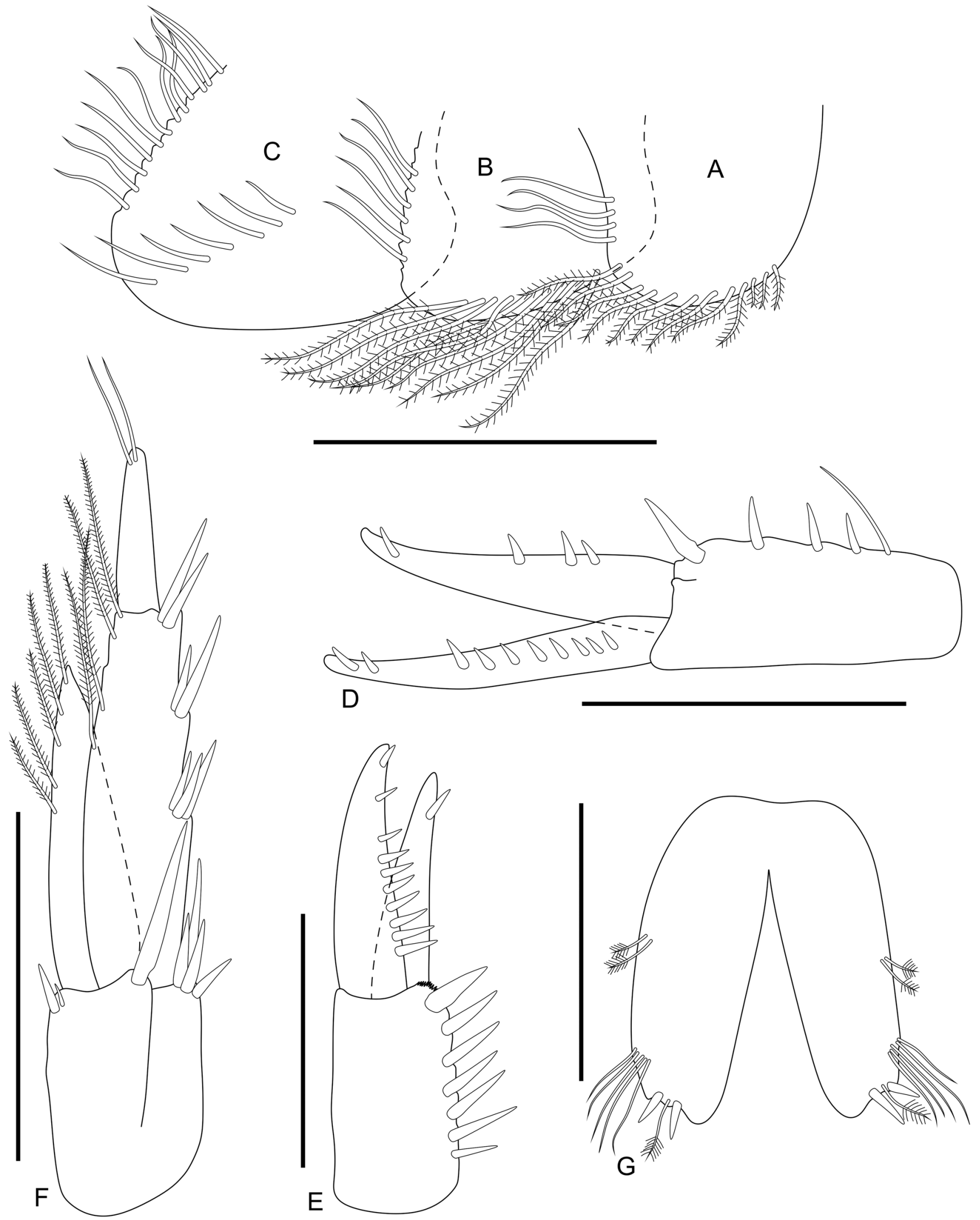

Figure 27. Microphoxus uroserratus Bustamante, 2002, female (UERJ 430): (A) Right epimeral plate 1; (B) Right epimeral plate 2; (C) Right epimeral plate 3; (D) Right uropod 1; (E) Right uropod 2; (F) Right uropod 3; (G) Telson. Scale bars: $0.3 \mathrm{~mm}$ for A; $0.1 \mathrm{~mm}$ for G; $0.2 \mathrm{~mm}$ for the remaining. 
Remarks: Since the material examined from station MBT 157 (UERJ 430) was partially damaged in the head and mouthparts, we selected a specimen from station MBT 163 (UERJ 431) to describe and draw mandibles, maxillae 1-2 and maxilliped.

Microphoxus uroserratus was described by Bustamante (2002) with material from Sepetiba Bay, Rio de Janeiro. The species was previously recorded for the states of Ceará (Barros et al., 2017), Paraná (Negrello-Filho et al., 2018) and Rio de Janeiro (Zalmon et al., 2013). As well as in Mi. cornutus, it is possible to notice morphological variations reflecting the maturation stages among the collected individuals of Mi. uroserratus in relation to the number of setae and armaments in antenna 2, pereopods, epimeral plates, uropods, and telson. On the original drawings by Bustamante (2002) it is possible to observe a lack of an acute lateral projection when analyzing the dorsal view of the head. However, it was possible to see this detail very clearly in our samples, leading us to suppose that this feature was overlooked during the description of the species.

Geographic distribution: Brazil: Sepetiba Bay and Campos Basin, Rio de Janeiro state; Goiabeiras Beach, municipality of Fortaleza, Ceará state; Paranaguá Bay inlet, Paraná state.

Bathymetric range: Shallow waters to $97 \mathrm{~m}$ depth.

\section{Identification key to world species of Microphoxus}

1 Rostrum very short, not exceeding apex of article 1 of antenna 1..........2

- Rostrum elongated, exceeding apex of article 1 of antenna 1................. 4

2 Pereopod 7, basis posterior margin crenulate to serrate, with 5-6 acute projections

- Pereopod 7, basis posterior margin serrate, with 3 acute projection ........

...Mi. minimus Barnard, 1960

3 Right mandible, incisor with 2 teeth, lacinia mobilis reduced

Mi. moraesi Bustamante, 2002

- Right mandible, incisor with 3 teeth, lacinia mobilis bifid ...Mi. cornutus (Schellenberg, 1931)

4 Uropods 1-2, rami shorter than peduncle..

..Mi. breviramus Bustamante, 2002

- Uropods 1-2, rami longer than peduncle

Mi. uroserratus Bustamante, 2002

\section{DISCUSSION}

Metharpinia Schellenberg, 1931, currently consists of 10 species distributed in North and South America. It was established for a single species, M. longirostris Schellenberg, 1931, from Valparaíso (Chile) and Buenos Aires (Argentina). Afterwards, Barnard (1980) described two new species, M. oripacifica Barnard, 1980 and M. coronadoi Barnard, 1980 from Costa Rica and California respectively, and transferred Paraphoxus jonesi Barnard, 1963 and Pontharpinia floridana Shoemaker, 1933 to Metharpinia.
Microphoxus Barnard, 1960 is formed of only 5 species spread along the Pacific and Atlantic coasts of the Americas. It was based on Mi. minimus Barnard, 1960, from Costa Rica, a species morphologically very close to Metharpinia.

In the past, Microphoxus and Metharpinia were distinguished from each other based only on the presence or absence, respectively, of a dorsally produced hook on urosomite 3 and an articulated nail on the maxilliped palp (Barnard, 1979). However, Barnard cautioned that these characteristics were not fully adequate for an appropriate generic distinction and predicted that further studies could reveal intermediate species between the two genera.

Alonso de Pina (2001), acknowledged that the definition between Metharpinia and Microphoxus, deserved further attention and later on (Alonso de Pina, $2003 a, b)$ concluded that the dorsal hook on the urosomite 3 was present in both Metharpinia dentiurosoma Alonso de Pina, 2003 and M. grandirama Alonso de Pina, 2003, and therefore could not be used as a distinctive feature between both genera. Alonso de Pina (2003b) submitted that Microphoxus differs from Metharpinia by the following characters (Metharpinia characters in parenthesis): antenna 1, article 2, ventral margin with setae placed widely spread (placed proximally); maxilliped, palp article 4 with articulated nail (partially fused); gnathopods 1-2, palms almost to totally transverse (acute); pereopods 3-4, propodus with thin facial setae (stout).

Both genera can be further distinguished from each other by the following characters (Metharpinia characters in parenthesis): antenna 2 , article 3 without facial setules (with 2 setules), article 4 with 1 or more rows of stout setae ( 2 or more rows); right mandible, molar with 3 or more splayed stout setae (4 or more); maxilliped, palp article 3 not protuberant (weakly protuberant); uropods 1-2, no rami with stout setae continuously to apex (1 or more rami with stout setae continuously to apex); uropod 3 , article 2 of outer ramus with 2 apical setae (2-3 apical setae). It should be noted, however, that Microphoxus uroserratus and Mi. breviramus are long-rostred species and, therefore, do not fully agree with the original diagnosis of the genus, whose species are typically short-rostred (viz. Barnard, 1960; Barnard \& Karaman, 1991).

\section{ACKNOWLEDGEMENTS}

The authors are grateful to Prof. Dr. Maria Teresa Valério-Berardo (Instituto Oceanográfico, Universidade de São Paulo) for providing the examined material. Also, we would like to thank Dr. Cédric d'Udekem d'Acoz (Royal Belgium Institute of Natural Sciences) and Dr. Marcos Tavares (Museu de Zoologia, Universidade de São Paulo) for the valuable comments and suggestions on this paper. This work is part of the Ph.D. Thesis of LFA in the PostGraduation Program in Animal Biology, Universidade Federal Rural do Rio de Janeiro (PPGBA - UFRRJ). This study was financed in part by the Coordenação de 
Aperfeiçoamento de Pessoal de Nível Superior - Brasil (CAPES) - Finance Code 001. ARS is supported by PROCIENCIA (UERJ) and Fundação Carlos Chagas Filho de Amparo à Pesquisa do Estado do Rio de Janeiro (FAPERJ), process number E-26/202.768/2019.

\section{REFERENCES}

Alonso de Pina, G.M. 2001. Two new phoxocephalids (Crustacea: Amphipoda: Phoxocephalidae) from the south-west Atlantic. Journal of Natural History, 35(4): 515-537.

Alonso de Pina, G.M. 2003a. A new species of Phoxocephalidae and some other records of sand-burrowing Amphipoda (Crustacea) from Argentina. Journal of Natural History, 37(9): 1029-2057.

Alonso de Pina, G.M. 2003b. Two new species of Metharpinia Schellenberg (Amphipoda: Phoxocephalidae) from the south-west Atlantic. Journal of Natural History, 37(21): 2521-2545.

Alonso de Pina, G.M.; Rauschert, M. \& De Broyer, C. 2008. A catalogue of the Antarctic and sub-Antarctic Phoxocephalidae (Crustacea: Amphipoda: Gammaridea) with taxonomic, distribution and ecological data. Zootaxa, 1752: $1-40$.

Alonso, G.M. 2012. Amphipod crustaceans (Corophiidea and Gammaridea) associated with holdfasts of Macrocystis pyrifera from the Beagle Channel (Argentina) and additional records from the Southwestern Atlantic. Journal of Natural History, 46(29-30): 1799-1894.

Alonso, G.M. \& Chiessa, I.L. 2014. Phoxocephalidae. In: Roig-Juñent, S.; Claps, L.E. \& Morrone, J.J. (Eds.). Biodiversidad de Artropódos Argentinos. Buenos Aires, INSUE-UNT. v. 3, p. 205-213.

Andrade, L.F.; Johnsson, R. \& Senna, A.R. 2015. Description of the first species of Metharpinia (Crustacea: Amphipoda: Phoxocephalidae) from Brazil. Zoologia, 32(1): 33-40.

Arasaki, E.; Muniz, P. \& Pires-Vanin, A.M.S. 2004. A functional analysis of the benthic macrofauna of the São Sebastião Channel (Southeastern Brazil). Marine Ecology, 25(4): 249-263.

Barnard, J.L. 1958. Index to the families, genera, and species of the Gammaridean Amphipoda (Crustacea). Allan Hancock Foundation Occasional Papers, 19: 1-145.

Barnard, J.L. 1960. The amphipod family Phoxocephalidae in the Eastern Pacific 0cean, with analyses of other species and notes for a revision of the family. Allan Hancock Pacific Expedition, 18: 175-368.

Barnard, J.L. 1979. Revision of American species of the marine amphipod genus Paraphoxus (Gammaridea: Phoxocephalidae). Proceedings of the Biological Society of Washington, 92(2): 368-379.

Barnard, J.L. 1980. Revision of Metharpinia and Microphoxus (Marine Phoxocephalid Amphipod from the Americas). Proceedings of the Biological Society of Washington, 93(1): 104-135.

Barnard, J.L. \& Drummond, M.M. 1976. Clarification of five genera of Phoxocephalidae (Marine Amphipoda). Proceedings of the Biological Society of Washington, 88(49): 515-549.

Barnard, J.L. \& Drummond, M.M. 1978. Gammaridean Amphipoda of Australia, Part III: The Phoxocephalidae. Smithsonian Contributions to Zoology, 245: 1-551.

Barnard, J.L. \& Karaman, G.S. 1991. The families and genera of marine gammaridean Amphipoda (except marine Gammaroidea). Parts 1-2. Records of the Australian Museum, 13(Suppl. 1-2): 1-866.

Barros, K.V.S.; Souza-Filho, J.F.; Paiva, R.J.C.; Araújo-Silva, C.L.; Almeida, A.0. \& Rocha-Barreira, C.A. 2017. Seasonal variation of the crustacean fauna in the belowground and aboveground strata in a Halodule wrightii meadow of northeastern Brazil. Iheringia, Série Zoologia, 107: 1-7, e2017048.
Bustamante, A. 2002. Three new species of Microphoxus Barnard, 1960 (Amphipoda, Phoxocephalidae, Metharpiniinae) from the coast of Rio de Janeiro, Brazil. Arquivos do Museu Nacional, 60(2): 55-78.

Chiesa, I.L. \& Alonso, G.M. 2007. Biodiversity of the Gammaridea and Corophiidea (Crustacea: Amphipoda) from the Beagle Channel and the Straits of Magellan: a preliminary comparison between their faunas. Revista de Biología Tropical, 55(1): 103-112.

Chiesa, I.L.; Alonso, G.M. \& Zelaya, D.G. 2005. Species richness and faunistic affinities of the Gammaridea and Corophiidea (Amphipoda) from shallow waters of southern Tierra del Fuego, Argentina: preliminary results. Scientia Marina, 69(2): 167-174.

Dahl, E. 1952. Some aspects of the ecology and zonation of the fauna on sandy beaches. Oikos, 4(1): 1-27.

De Broyer, C. \& Jażdżewski, K. 1993. Contributions to the marine biodiversity inventory. A checklist of the Amphipoda (Crustacea) of the Southern Ocean. Documents de Travail de I'Institut Royal des Sciences Naturelles de Belgique, 73: 1-154.

De Broyer, C. \& Rauschert, M. 1999. Faunal diversity of the benthic amphipods (Crustacea) of the Magellan region as compared to the Antarctic (preliminary results). Scientia Marina, 63(1): 281-293.

De Broyer, C.; Lowry, J.K.; Jazdzewski, K. \& Robert, H. 2007. Census of Antarctic Marine Life. Synopsis of the Amphipoda of the Southern Ocean. Part. 1. Catalogue of the Gammaridean and Corophiidean Amphipoda (Crustacea) of the Southern 0cean with distribution and ecological data. Bulletin de L'institut Royal Des Sciences Naturelles de Belgique, 77(1): 1-325.

Ferrando, A.; Esteves, J.L.; Elías, R. \& Méndez, N. 2010. Intertidal macrozoobenthos in sandy beaches of Bahía Nueva (Patagonia, Argentina) and their use as bioindicators of environmental impact. Scientia Marina, 74(2): 345-352.

Garm, A. \& Watling, L. 2013. The crustacean integument: setae, setules, and other ornamentation. In: Watling, L. \& Thiel, M. (Eds.). The natural history of the Crustacea. Functional morphology and diversity. 0xford, 0xford University Press. p. 167-198.

González, E. 1991. Actual state of gammaridean amphipoda taxonomy and catalogue of species from Chile. Hydrobiologia, 223: 47-68.

González, E.R.; Haye, P.A.; Balanda, M.J. \& Thiel, M. 2008. Lista sistematica de especies de peracaridos de Chile (Crustacea, Eumalacostraca). Gayana, 72(2): 157-177.

Jarrett, N.E. \& Bousfield, E.L. 1994. The amphipod superfamily Phoxocephaloidea on the pacific coast of North America. Family Phoxocephalidae. Part I. Metharpiniinae, new subfamily. Amphipacifica, 1(1): 58-140.

López-Gappa, J.; Alonso, G.M. \& Landoni, N.A. 2006. Biodiversity of benthic Amphipoda (Crustacea: Peracarida) in the Southwest Atlantic between $35^{\circ} \mathrm{S}$ and $56^{\circ} \mathrm{S}$. Zootaxa, 1342: 1-66.

Lowry, J.L. \& Bullock, S. 1976. Catalogue of the marine gammaridean Amphipoda of the Southern Ocean. The Royal Society of New Zealand, 16: 1-187.

Mendez, M.M.; Schwindt, E. \& Bortolus A. 2010. Relationships between macroinfaunal invertebrates and physicochemical factors in two sandy beaches of Patagonia. Journal of the Marine Biological Association of the United Kingdom, 90(3): 429-435.

Muniz, P.\& Pires-Vanin, A.M.S. 2005. More about taxonomic sufficiency: a case study using polychaete communities in a subtropical bay moderately affected by urban sewage. Ocean Science Journal, 40(3): 1-17.

Negrello-Filho, 0.A.; Ugaz-Codina, J.C.; Oliveira, L.H.S.; Souza, M.C. \& Angulo, R.J. 2018. Subtidal soft sediments of the Paranaguá Bay inlet: mapping habitats and species distribution at a landscape scale. Brazilian Journal of Oceanography, 66(3): 255-266. 
Pires-Vanin, A.M.S.; Arasaki, E. \& Muniz, P. 2013. Spatial pattern of benthic macrofauna in a sub-tropical shelf, São Sebastião Channel, southeastern Brazil. Latin American Journal of Aquatic Research, 41(1): 42-56.

Pires-Vanin, A.M.S.; Corbisier, T.N.; Arasaki, E. \& Möellmann, A.M. 1997. Composição e distribuição espaço-temporal da fauna bêntica no Canal de São Sebastião. Relatório Técnico do Instituto Oceanográfico, 41: 29-46.

Pires-Vanin, A.M.S.; Muniz, P. \& Bromberg, S. 2014. Inventory of the marine soft bottom macrofauna of São Sebastião Channel, southeastern Brazilian continental shelf. Check List, 10(4): 795-807.

Poore, A.G.B. \& Lowry, J.K. 1997. New ampithoid amphipods from Port Jackson, New South Wales, Australia (Crustacea: Amphipoda: Ampithoidae). Invertebrate Taxonomy, 11: 897-941.

Scelzo, M.A.; Arca, J.M. \& Lucero, N.M. 2002. Diversidad, densidad y biomasa de la macrofauna componente de los fondos de pesca "camarónlagostino", frente a Mar del Plata, Argentina (1998-1999). Revista de Investigación y Desarrollo Pesquero, 15: 43-65.

Schellenberg, A. 1931. Gammariden und Caprelliden des Magellangebietes, Südgeorgiens und der Westantarktis. Further Zoological Results. Swedish Antarctic Expedition 1901-1903, 2(6): 1-290.

Senna, A.R. 2010. A new genus and five new species of Phoxocephalidae (Crustacea: Amphipoda) from the south-east Brazilian deep sea. Journal of Natural History, 44(33-34): 2075-2118.

Serejo, C.S. \& Siqueira, S.G.L. 2018. Catalogue of the Order Amphipoda from Brazil (Crustacea, Peracarida): Suborders Amphilochidea, Senticaudata and Order Ingolfiellida. Zootaxa, 4431(1): 1-139.
Soto, E.; Quiroga, E.; Ganga, B. \& Alarcón, G. 2017. Influence of organic matter inputs and grain size on soft-bottom microbenthic biodiversity in the upwelling ecosystem of central Chile. Marine Biodiversity, 47(2): 433-450.

Valério-Berardo, M.T. 1992. Composição e distribuição da fauna de Amphipoda de fundos consolidados da região de Ubatuba (São Paulo, Brasil). (Doctoral Thesis). Universidade de São Paulo, Instituto Oceanográfico.

Valério-Berardo, M.T.; Flynn, M.N. \& Wakabara, Y. 2000. Structure and dynamics of a shelf amphipod taxocoenosis in southeastern Brazil. Bulletin of Marine Science, 66(1): 59-72.

Wakabara, Y. \& Serejo, C.S. 1998. Malacostraca - Peracarida. Amphipoda. Gammaridea and Caprellidea. In: Young, P.S. (Ed.). Catalogue of Crustacean of Brazil. Rio de Janeiro, Museu Nacional. p. 561-594. (Série Livros № 6).

Wakabara, Y.; Rezende, E.K. \& Tararam, A.S. 1982. Amphipod as one of the main food components of three Pleuronectiformes from the continental shelf of south Brazil and north Uruguay. Marine Biology, 68: 67-70.

Wakabara, Y.; Tararam, A.S.; Valério-Berardo, M.T.; Duleba, W. \& Leite, F.P.P. 1991. Gammaridean and Caprellidean fauna from Brazil. Hydrobiologia, 223: 69-77.

Zalmon, I.R.; Macedo, I.M.; Rezende, C.E.; Falcão, A.P.C. \& Almeida, T.C. 2013. The distribution of macrofauna on the inner continental shelf of southeastern Brazil: The major influence of an estuarine system. Estuarine, Coastal and Shelf Science, 130: 169-178. 